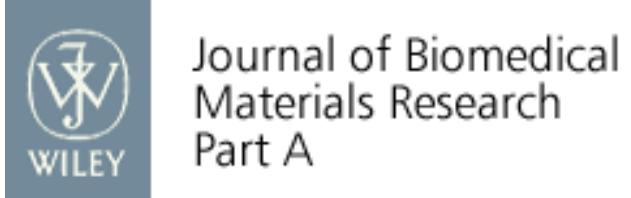

\title{
Novel multicomponent organic-inorganic WPI/gelatin/CaP hydrogel composites for bone tissue engineering
}

\begin{tabular}{|c|c|}
\hline Journal: & Journal of Biomedical Materials Research: Part A \\
\hline Manuscript ID & JBMR-A-19-0199.R1 \\
\hline Wiley - Manuscript type: & Original Article \\
\hline $\begin{array}{r}\text { Date Submitted by the } \\
\text { Author: }\end{array}$ & $\mathrm{n} / \mathrm{a}$ \\
\hline Complete List of Authors: & $\begin{array}{l}\text { Dziadek, Michal; AGH University of Science and Technology, Faculty of } \\
\text { Materials Science and Ceramics, Department of Glass Technology and } \\
\text { Amorphous Coatings } \\
\text { Kudlackova, Radmila; Czech Academy of Sciences, Institute of } \\
\text { Physiology } \\
\text { Zima, Aneta; AGH UST University of Science and Technology, } \\
\text { Department of Ceramic and Refractories } \\
\text { Elósarczyk, Anna; AGH-University of Science and Technology, Faculty of } \\
\text { Materials Science and Ceramics } \\
\text { Ziabka, Magdalena; AGH University of Science and Technology, Faculty } \\
\text { of Materials Science and Ceramics, Department of Glass Technology and } \\
\text { Amorphous Coatings } \\
\text { Jelen, Piotr; AGH University of Science and Technology, Faculty of } \\
\text { Materials Science and Ceramics, Al. Mickiewicza 30, 30-059 Cracow, } \\
\text { Poland., Dept. Silicate Chemistry and Macromolecular Compounds } \\
\text { Shkarina, Svetlana; National Research Tomsk Polytechnic University, } \\
\text { Research Center Physical Materials Science and Composite Materials } \\
\text { Cecilia, Angelica; Karlsruhe Institute of Technology, Institute for Photon } \\
\text { Science and Synchrotron Radiation } \\
\text { Zuber, Marcus; Karlsruhe Institute of Technology, Institute for Photon } \\
\text { Science and Synchrotron Radiation } \\
\text { Baumbach, Tilo; Karlsruhe Institute of Technology, Laboratory for } \\
\text { Applications of Synchrotron Radiation, } \\
\text { Surmeneva, Maria; National Research Tomsk Polytechnic University, } \\
\text { Research Center Physical Materials Science and Composite Materials } \\
\text { Surmenev, Roman; National Research Tomsk Polytechnic University, } \\
\text { Dept. Theoretical and Experimental Physics } \\
\text { Bacakova, Lucie; Institute of Physiology, Academy of Sciences of the } \\
\text { Czech Republic,, Department of Biomaterials and Tissue Engineering } \\
\text { Cholewa-Kowalska, Katarzyna; AGH University of Science and } \\
\text { Technology, Departament of Glass Technology and Amorphous Coatings, } \\
\text { Faculty of Materials Science and Ceramics } \\
\text { Douglas, Timothy; Lancaster University, Engineering Department }\end{array}$ \\
\hline Keywords: & whey protein isolate, gelatin, calcium phosphate, hydrogel composites \\
\hline
\end{tabular}




\section{SCHOLARONE ${ }^{\text {TM }}$ Manuscripts}

John Wiley \& Sons, Inc. 


\section{Novel multicomponent organic-inorganic WPI/gelatin/CaP hydrogel composites for bone tissue engineering}

Michal Dziadek ${ }^{1,2,3 *}$, Radmila Kudlackova ${ }^{3,4}$, Aneta Zima ${ }^{2}$, Anna Slosarczyk ${ }^{2}$, Magdalena Ziabka $^{2}$, Piotr Jelen ${ }^{5}$, Svetlana Shkarina ${ }^{6}$, Angelica Cecilia ${ }^{7}$, Marcus Zuber ${ }^{7,8}$, Tilo

Baumbach $^{7,8}$, Maria A. Surmeneva ${ }^{6}$, Roman A. Surmenev ${ }^{6}$, Lucie Bacakova ${ }^{4}$, Katarzyna Cholewa-Kowalska ${ }^{1}$, Timothy E.L. Douglas 3,9

${ }^{1}$ Dept. Glass Technology and Amorphous Coatings, AGH University of Science and Technology, Krakow, Poland;

${ }^{2}$ Dept. Ceramics and Refractories, AGH University of Science and Technology, Krakow, Poland; ${ }^{3}$ Engineering Dept., Lancaster University, United Kingdom;

${ }^{4}$ Institute of Physiology, Czech Academy of Sciences, Prague, Czech Republic

${ }^{5}$ Dept. Silicate Chemistry and Macromolecular Compounds; AGH University of Science and Technology, Krakow, Poland;

${ }^{6}$ Research Center Physical Materials Science and Composite Materials, National Research Tomsk Polytechnic University, Russian Federation;

${ }^{7}$ Institute for Photon Science and Synchrotron Radiation, Karlsruhe Institute of Technology, Eggenstein-Leopoldshafen, Germany;

${ }^{8}$ Laboratory for Applications of Synchrotron Radiation, Karlsruhe Institute of Technology, Eggenstein-Leopoldshafen, Germany;

${ }^{9}$ Materials Science Institute (MSI), Lancaster University, United Kingdom;

*Corresponding Author. Email: dziadek@agh.edu.pl 


\begin{abstract}
:
The present work focuses on the development of novel multicomponent organic-inorganic hydrogel composites for bone tissue engineering. For the first time, combination of the organic components commonly used in food industry, namely whey protein isolate (WPI) and gelatin from bovine skin, as well as inorganic material commonly used as a major component of hydraulic bone cements, namely $\alpha$-TCP in various concentrations $(0-70 \mathrm{wt} . \%)$ was proposed. The results showed that $\alpha$-TCP underwent incomplete transformation to calcium-deficient hydroxyapatite (CDHA) during preparation process of the hydrogels. Microcomputer tomography showed inhomogeneous distribution of the calcium phosphate $(\mathrm{CaP})$ phase in the resulting composites. Nevertheless, hydrogels containing 30-70 wt.\% $\alpha$-TCP showed significantly improved mechanical properties. The values of Young's modulus and the stresses corresponding to compression of a sample by $50 \%$ increased almost linearly with increasing concentration of ceramic phase. Incomplete transformation of $\alpha$-TCP to CDHA during preparation process of composites provides them high reactivity in simulated body fluid during 14-day incubation. Preliminary in vitro studies revealed that the WPI/gelatin/CaP composite hydrogels support the adhesion, spreading, and proliferation of human osteoblast-like MG-63 cells. The WPI/gelatin/CaP composite hydrogels obtained in this work showed great potential for the use in bone tissue engineering and regenerative medicine applications.
\end{abstract}

Keywords: whey protein isolate; gelatin; calcium phosphate; hydrogel composites; 


\section{Introduction}

Hydrogels due to their structural similarity to the natural extracellular matrix (ECM), high water content and high permeability for oxygen, nutrients and metabolites have been extensively studied in tissue engineering. However, using hydrogels for this application is still limited primarily because of relatively low mechanical strength. What is more, many hydrogels do not exhibit biological activities that are necessary to facilitate tissue regeneration. Therefore, recent efforts are focusing on the development of multifunctional hydrogels with enhanced mechanical properties and controlled biological functions. One approach is to combine various materials to obtain multicomponent hydrogels ${ }^{(1)}$. The second possibility is to modify hydrogel matrix with ceramic particles to produce composite materials. These multicomponent systems can better mimic the native ECM, as they consists of multiple structural and functional constituents. In this study, the combination of the above-mentioned approaches was proposed. Threecomponent hydrogels, consisting of whey protein isolate (WPI) as a main hydrogel matrix component, gelatin $(\mathrm{Gel})$ as a matrix modifier, as well as alpha-tricalcium phosphate $(\alpha-\mathrm{TCP})$ as ceramic filler, were produced.

Whey proteins constitute $20 \%$ of all proteins in milk and include mainly $\beta$-lactoglobulin $(\beta-\mathrm{Lg})$, $\alpha$-lactalbumin ( $\alpha$-La) and smaller amounts of glycomacropeptide (GMP), immunoglobulins (Igs), bovine serum albumin (BSA), lactoferrin (LF), lactoperoxidase (LP), and proteose peptone $(\mathrm{PP})^{(2)}$. Whey proteins are considered as a by-product of cheese manufacturing, hence they are extremely inexpensive and abundantly available in various forms (concentrates, hydrolysates, and isolates). They are used widely in food industry primarily as an emulsifying, thickening, gelling, foaming, and water-binding agent. The whey derivates are also used in pharmaceutical and cosmetic products as pigments ${ }^{(2),(3)}$. Heat treatment of an aqueous solution of whey protein isolate above $60{ }^{\circ} \mathrm{C}$ results in unfolding of the proteins followed by the formation of bonds between them, leading to the formation of the a three-dimensional network 
filled by water - hydrogel (2). Biodegradability and ability of WPI to form a hydrogel without the use of chemical cross-linking agents makes it attractive for use in biomedical applications. WPI hydrogels can be used as bioresponsive carriers for controlled release of biomolecules and drugs, as they exhibit good $\mathrm{pH}$-sensitivity ${ }^{(4)}$. Furthermore, our previous research indicated that the WPI dissolved in cell culture medium support proliferation of human osteoblast-like Saos2 cells and human neonatal dermal fibroblasts (FIB), and also enhance osteogenic differentiation of human adipose tissue-derived stem cells (ASC). ${ }^{(5)}$. This suggests that WPI can be promising component of hydrogels for bone tissue regeneration.

Gelatin is produced by thermal denaturation or physical and chemical degradation of collagen. Due to its biocompatibility, non-immunogenic properties, high availability, and low cost, gelatin is used in the pharmaceutical and biomedical applications as microspheres, capsules, wound dressing and surgical absorbent pads. In order to overcome its limitations including high degradation rate in aqueous environment and weak mechanical properties, chemical crosslinking agents, such as formaldehyde, glyoxal, glutaraldehyde, genipin, and transglutaminase, are used ${ }^{(6),(7)}$. Since, gelatin contains Arg-Gly-Asp (RGD) sequences that promote cell adhesion and spreading, it has been blended with other polymers (e.g. chitosan, alginate, PVA, starch/chitosan) to obtain hydrogels with improved biological activity ${ }^{(8)-(11)}$. Alpha-tricalcium phosphate exhibit one of the highest chemical reactivity among calcium phosphate $(\mathrm{CaP})$ ceramics. It reacts with aqueous media to form calcium-deficient hydroxyapatite (CDHA) ${ }^{(12)}$. $\alpha$-TCP exhibits bioactivity as it is able to form direct chemical bond with the native bones. Some research has indicated that $\mathrm{Ca}^{2+}$ and $\mathrm{PO}_{4}{ }^{3-}$ ions released from $\alpha$-TCP structure can stimulate osteogenic differentiation of the BMSCs and bone matrix mineralization ${ }^{(13)}$. Our previous studies have indicated that $\alpha$-TCP incorporated into gellan gum (GG) hydrogel matrix hydrolyzes to a CDHA crystals in situ during composite production. Addition of inorganic particles into hydrogel matrices provides widespread strategy of hydrogel 
mineralization, supporting mechanical strength and osteogenic differentiation of bone-forming cells. As was suggested, $\alpha$-TCP-CDHA transformation would result in mechanical interlocking of particles, providing additionally enhanced mechanical properties of resulting materials ${ }^{(14)}$.

The novelty of this work is to apply WPI as an inexpensive and abundantly available component to produce composite hydrogels for biomedical applications using two-step cold- and heatinduced gelation technique. It was hypothesized that the addition of gelatin to WPI matrix would allow one to obtain materials supporting cell adhesion and growth, while the incorporation of ceramic phase would improve their mechanical properties. We tested the effect of different concentrations of $\alpha$-TCP in WPI/gelatin matrix on (i) the ability of $\alpha$-TCP phase transformation to CDHA during hydrogel synthesis; (ii) morphology and distribution of ceramic phase within the hydrogel matrix; (iii) mechanical properties of hydrogels; (iv) hydrogel behavior upon incubation in simulated body fluid; and (v) in vitro human osteoblastlike MG-63 cell response.

\section{Materials and Methods}

\subsection{Materials}

Whey protein isolate (BiPro, Davisco Foods International Inc., USA) containing $97.7 \%$ of protein and $75 \%$ of $\beta$-LG in dry mass, according to the manufacturer's specification, and gelatin from bovine skin type B (Sigma-Aldrich, UK) were used. $\alpha$-TCP was produced by the wet chemical method as described previously ${ }^{(12)(15)}$. $\alpha$-TCP particle size distribution was measured in previous work ${ }^{(14)}$.

All materials were obtained from Sigma-Aldrich, unless stated otherwise.

\subsection{Production of WPI/gelatin/CaP hydrogel composites}

To produce composites, $40 \mathrm{wt} . /$ vol.\% aqueous WPI solution was mixed with gelatin powder $(20 \mathrm{wt} \%)$ in ultrasonic bath $\left(40^{\circ} \mathrm{C}\right)$ for $30 \mathrm{~min}$. Warm WPI/gelatin solution was mixed with $\alpha-$ 
TCP powder in $2 \mathrm{~mL}$ Eppendorf tubes using vortex mixer (Vortex-Genie 2, Scientific Industries Inc., USA) for $30 \mathrm{~s}$. Tightly closed Eppendorf tubes were immersed in cold $\left(-20^{\circ} \mathrm{C}\right)$ ethanol to induce fast gelation. After 2 minutes, tubes were immediately transferred to thermoblock (ThermoMixer C, Eppendorf, USA) and held at $100{ }^{\circ} \mathrm{C}$ for 5 min to induce WPI thermal crosslinking. To ensure complete crosslinking and sterility, materials were autoclaved $\left(121^{\circ} \mathrm{C}\right.$ for $30 \mathrm{~min}$ ). After autoclaving, Eppendorf tubes containing materials were tightly closed under sterile conditions (in a laminar flow hood) and stored at $4{ }^{\circ} \mathrm{C}$ until further investigation. Materials with $\alpha$-TCP of final concentrations of 20, 30, 40, 50, 60, and $70 \mathrm{wt} \%$ were denoted as WPI/Gel/20TCP, WPI/Gel/30TCP, WPI/Gel/40TCP, WPI/Gel/50TCP, WPI/Gel/60TCP, and WPI/Gel/70TCP, respectively.

\subsection{Structural analysis}

The XRD analysis of hydrogels was performed using SmartLab 9kW diffractometer (Rigaku, Japan) in the $2 \theta$ range of $10-50^{\circ}$ with $\mathrm{CuK} \alpha$ radiation source and $0.008^{\circ}$ step size in Bragg Brentano configuration.

FTIR spectra were recorded with the Vertex 70v spectrometer (Bruker, USA). Samples were prepared by the standard $\mathrm{KBr}$ pellet method. Spectra were collected in the middle infrared $4000-400 \mathrm{~cm}^{-1}$ range (MIR), and 128 scans were accumulated at $4 \mathrm{~cm}^{-1}$ resolution.

Raman studies were conducted using LabRAM HR micro Raman spectrometer (Horiba, Japan). The exciting $532 \mathrm{~nm}$ laser power was set to $15 \mathrm{~mW}$. The $1800 \mathrm{gr} / \mathrm{mm}$ grating with $100 \mathrm{x}$ objectives were used and 2 scans of $300 \mathrm{~s}$ each were accumulated.

Before XRD, FTIR, and Raman analyses, materials were frozen at $-24{ }^{\circ} \mathrm{C}$ and subsequently subjected to a lyophylization process in order to obtain dry mass. Freeze-drying was performed using FreeZone 6 Liter Freeze Dry System (Labconco, USA) for 48 hours.

\subsection{Nondestructive micro-computed tomography $(\mu C T)$ imaging}


Materials were imaged in Eppendorf tubes with a laboratory X-ray source at the CT Lab of the Institute for Photon Science and Synchrotron Radiation at the Karlsruhe Institute of Technology (Karlsruhe, Germany). For X-ray tomography acquisitions, a microfocus X-ray tube (XWT225-SE X-ray worX, Germany) with a tungsten target was set to $60 \mathrm{kV}$ voltage and to $15 \mathrm{~W}$ target power. The source-object distance and source-detector distance were adjusted to 100 and $1710 \mathrm{~mm}$, respectively, with a spatial resolution of $11 \mu \mathrm{m}$ and a field of view of $23,8 \times 23,8$ $\mathrm{mm}^{2}$. For each measurement, a series of 2048 projection images were taken over a $360^{\circ}$ angular range with an exposure time of $5 \mathrm{~s}$. The three-dimensional (3D) volumes were reconstructed with Octopus software. Segmentation of particles agglomerates was done using the Shanbhag thresholding method. Rendering and visualization of segmented agglomerates in 3D was performed by means of Amira 5.4.5 software.

\subsection{Mechanical testing}

Cylindrical samples of $9 \mathrm{~mm}$ diameter and $18 \mathrm{~mm}$ height were tested in uniaxial compression using a universal testing machine Inspect Table Blue $5 \mathrm{kN}$ with $5 \mathrm{kN}$ load cell (Hegewald\&Peschke, Germany). The loading rate of compression was $5 \mathrm{~mm} \mathrm{~min}^{-1}$ and the preload force was $1 \mathrm{~N}$. The Young's modulus $\left(\mathrm{E}_{\mathrm{C}}\right)$ was calculated from the initial linear part of the slope of the stress-strain curve. Furthermore, the stresses corresponding to compression of a sample by $50 \%\left(\sigma_{50 \%}\right)$ was determined. Mechanical parameters were calculated by averaging ten measurements and were expressed as mean \pm standard deviation (SD).

\subsection{Mineralization studies in SBF}

Simulated body fluid (SBF) was prepared according to Kokubo ${ }^{(16)}$. WPI/Gel, WPI/Gel/20TCP, WPI/Gel/40TCP, WPI/Gel/60TCP, and WPI/Gel/70TCP hydrogels were incubated in SBF solution at $37^{\circ} \mathrm{C}$ in separate containers for 7 and 14 days under sterile conditions. The ratio of the composite hydrogel's weight $(\mathrm{g})$ and solution's volume $(\mathrm{ml})$ was $1 / 100$. Afterwards the materials were taken out of $\mathrm{SBF}$, frozen at $-24{ }^{\circ} \mathrm{C}$ and subsequently subjected to a 
lyophylization process in order to obtain dry mass. Freeze-drying was performed using FreeZone 6 Liter Freeze Dry System (Labconco, USA) for 48 hours.

After incubation in SBF, hydrogels were analyzed using XRD and FTIR methods as described above. Before and after incubation in SBF, microstructure of the hydrogels was determined using SEM (Nova NanoSEM 200 FEI Europe Company). Materials were analyzed after coating with a thin conductive carbon layer. The changes in $\mathrm{Ca}$ and $\mathrm{P}$ concentration in the SBF was monitored using an ICP-OES technique (Plasm 40, Perkin Elmer, USA). For all sample groups, $\mathrm{n}=3$.

\subsection{In vitro biological characterization with osteoblastic cells}

Materials were cut to $1 \mathrm{~mm}$ thick slices in sterile conditions and placed in a 48-well culture plate. Human osteoblast-like MG-63 cells (Sigma Aldrich, USA) was seeded on materials in a concentration of $10.5 \times 10^{3} \mathrm{~cm}^{-2}$ in $1 \mathrm{ml}$ of culture media. DMEM culture media (Sigma Aldrich, USA) was supplemented with 10\% FBS (Thermo Fisher Scientific, USA) and penicillin/streptomycin (100 IU/ml, $100 \mu \mathrm{g} / \mathrm{ml}$; Sigma Aldrich, USA). Cell cultivation was performed for 3 or 7 days under conditions of $37^{\circ} \mathrm{C}$ and $5 \% \mathrm{CO}_{2}$.

Cell adhesion, morphology and proliferation were observed by confocal microscopy. The cells were rinsed with PBS and fixed in $-20{ }^{\circ} \mathrm{C} 70 \%$ ethanol for $10 \mathrm{~min}$. After fixation, the materials were rinsed with PBS and cell nuclei were stained with Hoechst 33342 (final concentration of $0.5 \mu \mathrm{g} / \mathrm{ml}$; blue color, wavelength $\max \lambda_{\mathrm{ex}}=350 \mathrm{~nm}, \lambda_{\mathrm{em}}=461 \mathrm{~nm}$; Thermo Fisher Scientific, USA) and cell cytoplasm with Texas Red C2 maleimide (final concentration of $50 \mathrm{ng} / \mathrm{ml}$; red color, wavelength $\max \lambda_{\mathrm{ex}}=595 \mathrm{~nm}, \lambda_{\mathrm{em}}=615 \mathrm{~nm}$; Thermo Fisher Scientific, USA) diluted in PBS for $15 \mathrm{~min}$ in dark conditions. The materials were rinsed twice with PBS before microscopy. Images were taken using a ZEISS LSM 880 confocal microscope. 
Cell viability and proliferation were determined using CellTiter 96 AQueous One Solution Cell Proliferation Assay (MTS; Promega, USA). 3 samples for each sample group and time interval were used. The materials were rinsed with PBS and cultured in a $0.5 \mathrm{ml}$ of a mixture (1:6) of the MTS kit with DMEM without phenol red (Sigma Aldrich, USA) supplemented with 10\% FBS for 2 hours under cell culture conditions. Absorbance was measured at a $490 \mathrm{~nm}$ wavelength by plate reader Infinite M200 Pro (Tecan, Switzerland).

\subsection{Statistical analysis}

The results were analyzed using one-way analysis of variance (ANOVA) with Duncan post hoc tests, which were performed with Statistica 13.1 (Dell Inc., USA) software. The results were considered statistically significant when $\mathrm{p}<0.05$.

\section{Results}

\subsection{Structural analysis}
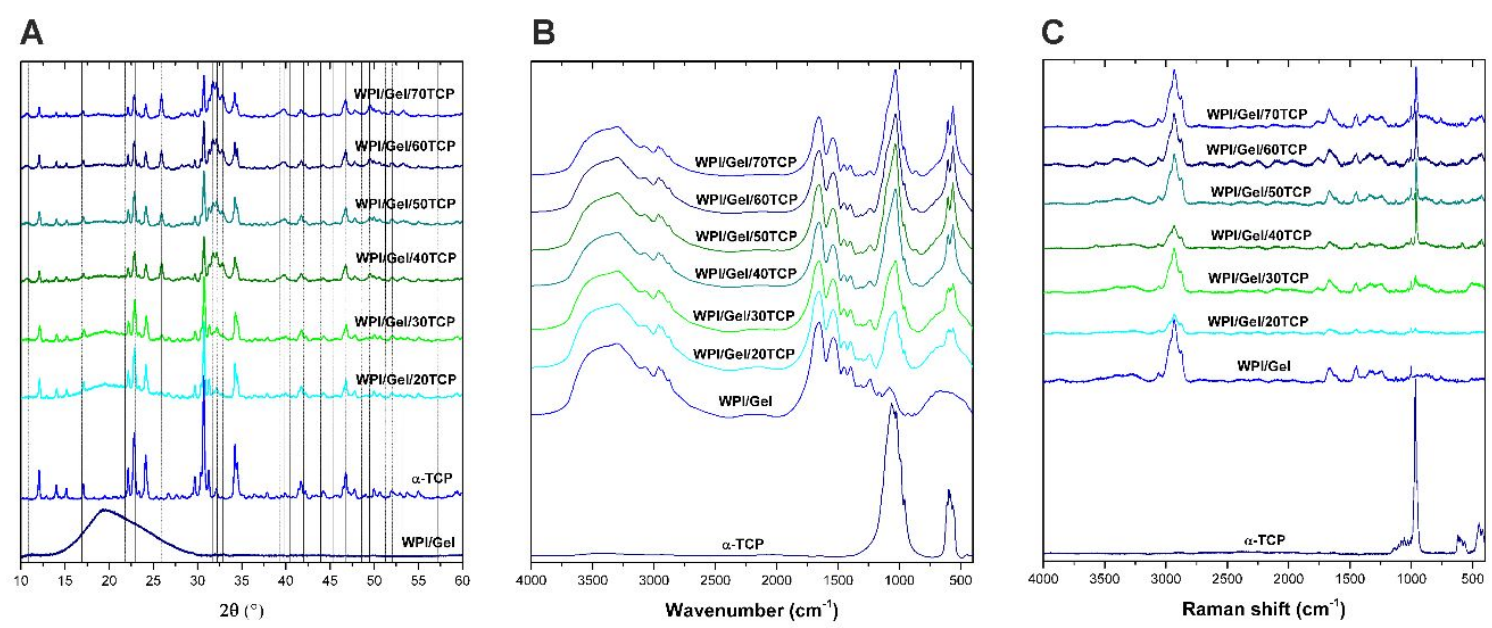

Figure 1. XRD patterns (A), FTIR (B) and Raman (C) spectra of the WPI/gelatin/CaP hydrogels. XRD reflexes characteristic of hydroxyapatite are indicated by doted lines. 
XRD analysis, as well as FTIR and Raman spectroscopies indicated the transformation of $\alpha$ TCP to CDHA in all composite hydrogels. XRD patterns of composite materials (Fig. 1A) revealed a number of new reflexes characteristic of $\mathrm{HA}\left(10.78^{\circ}, 25.90^{\circ}, 28.91^{\circ}, 31.72^{\circ}, 32.17^{\circ}\right.$, $\left.32.85^{\circ}, 39.78^{\circ}, 49.46^{\circ}, 53.27^{\circ} 2 \theta\right)$. Their intensities increased with increasing initial content of $\alpha$-TCP in composites. The pattern of WPI/gelatin hydrogel exhibits a hump in the range of $15^{\circ}-$ $30^{\circ} 2 \theta$, characteristic of the amorphous structure. A hump is also observed for composite materials containing lower initial content of $\alpha$-TCP. Its intensity gradually decreases with increasing content of inorganic phase in composites.

In the FTIR spectrum of $\alpha$-TCP (Fig. 1B), the strongest bands at the 900-1200 and 500-650 $\mathrm{cm}^{-1}$ regions are attributed to the vibrations of $\mathrm{PO}_{4}{ }^{3-}$ groups. Band at $956 \mathrm{~cm}^{-1}$ is characteristic of symmetric P-O stretching $\left(v_{1}\right)$ mode. In the ranges of $986-1062 \mathrm{~cm}^{-1}$ and $551-610 \mathrm{~cm}^{-1}$ antisymmetric $\mathrm{P}-\mathrm{O}$ stretching $\left(v_{3}\right)$ and antisymmetric $\mathrm{O}-\mathrm{P}-\mathrm{O}$ bending $\left(v_{4}\right)$ mode occur, respectively (17),(18). In the FTIR spectra of WPI/gelatin/CaP hydrogel composites, bands characteristic of hydroxyapatite are present. Double, sharp bands in the range of 563-603 $\mathrm{cm}^{-1}$ and strong band at $1030 \mathrm{~cm}^{-1}$ with a shoulder at $1095 \mathrm{~cm}^{-1}$ arise from the anti-symmetric O-P$\mathrm{O}$ bending $\left(v_{4}\right)$ and antisymmetric $\mathrm{P}-\mathrm{O}$ stretching $\left(v_{3}\right)$ vibrations of $\mathrm{PO}_{4}{ }^{3-}$ groups in $\mathrm{HA}$, respectively ${ }^{(19)}$. Furthermore, the weak band at $865 \mathrm{~cm}^{-1}$ derives from $\mathrm{P}-\mathrm{O}(\mathrm{H})$ stretching vibrations of $\mathrm{HPO}_{4}{ }^{2-}$, indicates the presence of CDHA (20),(21). The intensities of bands characteristics of HA/CDHA increase with increasing initial content of $\alpha$-TCP in materials.

The Raman spectrum of $\alpha$-TCP exhibits strong double bands at 964 and $972 \mathrm{~cm}^{-1}$ with a shoulder at $954 \mathrm{~cm}^{-1}$, corresponding to the symmetric P-O stretching $\left(v_{1}\right)$ mode (Fig. 1C). Weak bands at the ranges of $420-450 \mathrm{~cm}^{-1}, 998-1077 \mathrm{~cm}^{-1}$, and $563-620 \mathrm{~cm}^{-1}$ can be assigned to symmetric $\mathrm{O}-\mathrm{P}-\mathrm{O}$ bending $\left(\mathrm{v}_{2}\right)$, antisymmetric $\mathrm{P}-\mathrm{O}$ stretching $\left(\mathrm{v}_{3}\right)$, and antisymmetric $\mathrm{O}-\mathrm{P}-\mathrm{O}$ bending $\left(v_{4}\right)$ vibrations of $\mathrm{PO}_{4}{ }^{3-}$ groups in $\alpha$-TCP, respectively ${ }^{(17),(18)}$. The Raman spectra of WPI/gelatin/CaP hydrogel composites reveal bands characteristic of hydroxyapatite. Bands at 
962 and $1046 \mathrm{~cm}^{-1}$ derive from $\mathrm{P}-\mathrm{O}$ stretching modes ( $v_{1}$ and $v_{3}$, respectively), while bands at 420 and $589 \mathrm{~cm}^{-1}$ arise from $\mathrm{O}-\mathrm{P}-\mathrm{O}$ bending modes ( $v_{2}$ and $v_{4}$, respectively) ${ }^{(21),(22)}$. The intensities of bands characteristics of HA increase, while the bands derived from $\alpha$-TCP diminish with increasing initial content of $\alpha$-TCP in materials. Also new band at $3570 \mathrm{~cm}^{-1}$ corresponding to the stretching mode of $-\mathrm{OH}$ group in the CDHA lattice was observed for composites containing 40-70 wt.\% $\alpha$-TCP ${ }^{(23)}$.

\subsection{Mechanical testing}

A

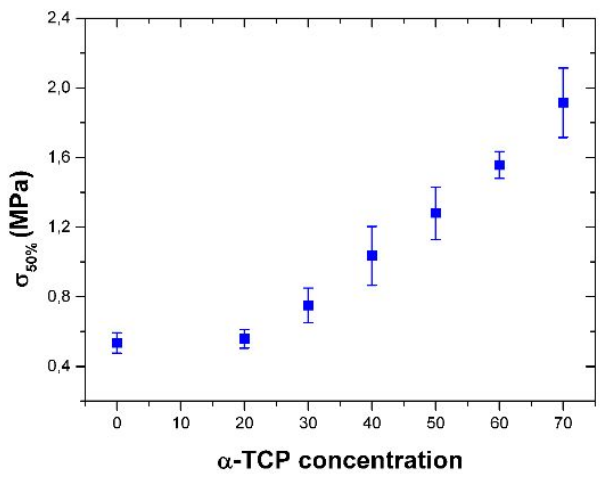

B

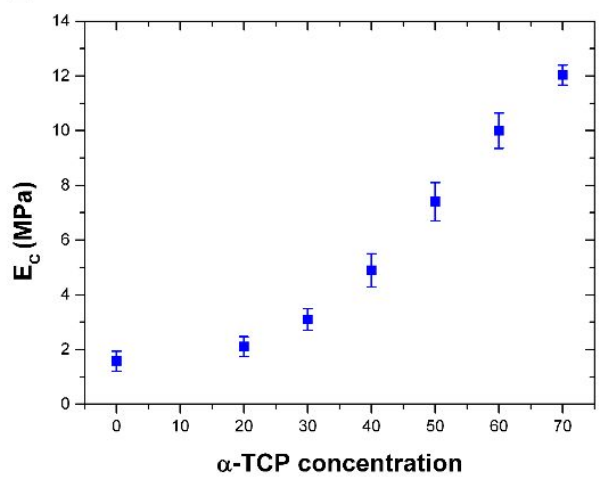

Figure 2. Compressive strength at $50 \%$ strain $\sigma_{50 \%}(\mathrm{~A})$ and compressive modulus $\mathrm{E}_{\mathrm{C}}(\mathrm{B})$ of the WPI/gelatin/CaP hydrogel composites.

The presence of $20 \mathrm{wt} \% \quad \alpha$-TCP in the composite hydrogel (WPI/Gel/20TCP) did not affect significantly the compressive strength at $50 \%$ strain and compressive modulus (Figs. 2A-2B). Composites containing 30-70 wt.\% $\alpha$-TCP showed improved mechanical properties $-\sigma_{50 \%}$ and $\mathrm{E}_{\mathrm{C}}$ increased almost linearly with increasing concentration of ceramic phase. WPI/Gel/70TCP showed more than 7.5-fold increase in $\mathrm{E}_{\mathrm{C}}$ and more than 3.5-fold increase in $\sigma_{50 \%}$ compared to unmodified hydrogel. The results clearly indicate that by the modification of WPI/gelatin hydrogels with different amounts of $\alpha$-TCP the stiffness and compressive strength can be tuned in a wide range. 
Interestingly, the presence of $\mathrm{CaP}$ phase in hydrogel matrix resulted an improvement of the mechanical properties, despite the increased porosity (Fig. 4).

\section{$3.3 \mu C T$ examination}
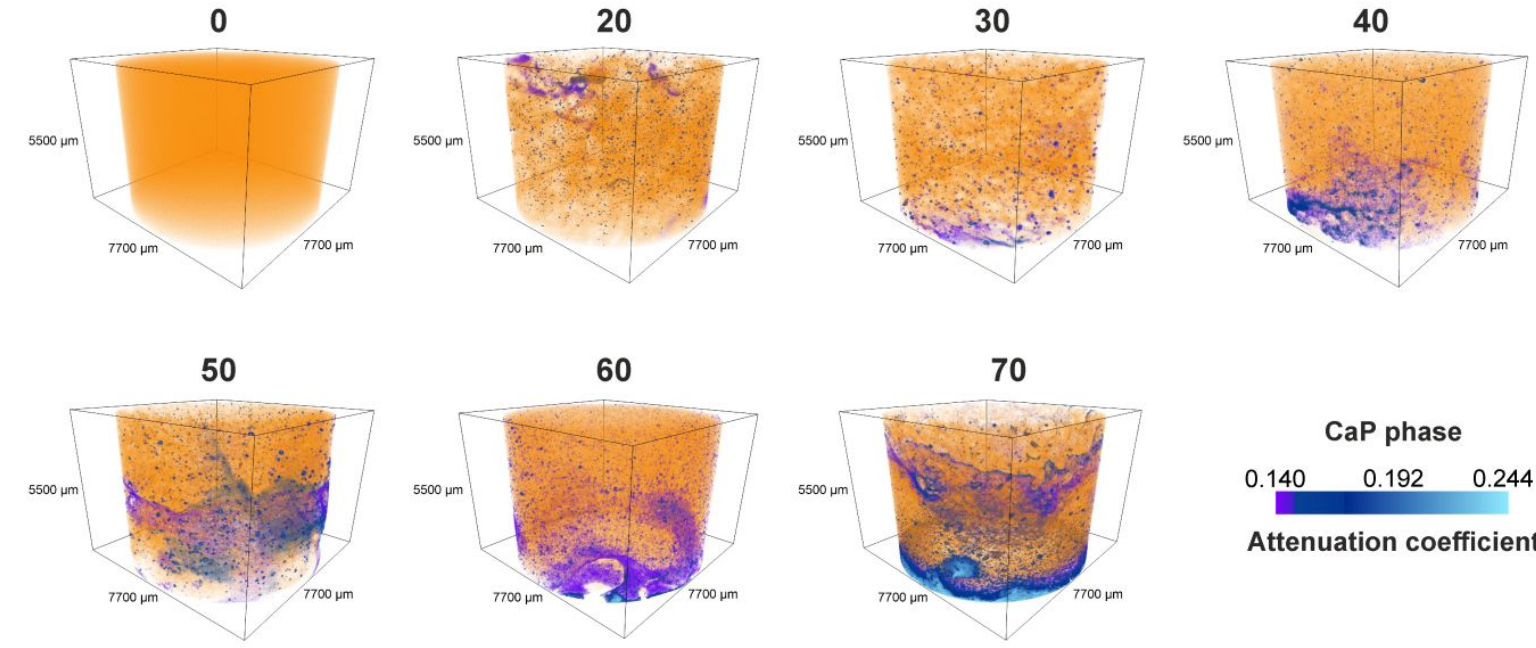

Figure 3. $\mu \mathrm{CT}$ analysis of the WPI/gelatin/CaP hydrogels - 3D rendering.

3D $\mu \mathrm{CT}$ reconstructions of WPI/gelatin/CaP composite hydrogels are shown in Figure 3 . The slices extracted from the bottom, middle and top position of each tomography reconstruction are presented in Figure 4. It can be seen that $\mathrm{CaP}$ phase was distributed inhomogeneously throughout the hydrogel matrices (Figs. 3 and 4). Regions of $\mathrm{CaP}$ phase in resulting composites were much larger than $\alpha$-TCP particles introduced during hydrogel preparation process. The incorporation of $\mathrm{CaP}$ phase in $\mathrm{WPI} /$ gelatin matrix generated material porosity. The porosity increased with increasing distance from the bottom position of the composite hydrogels. 


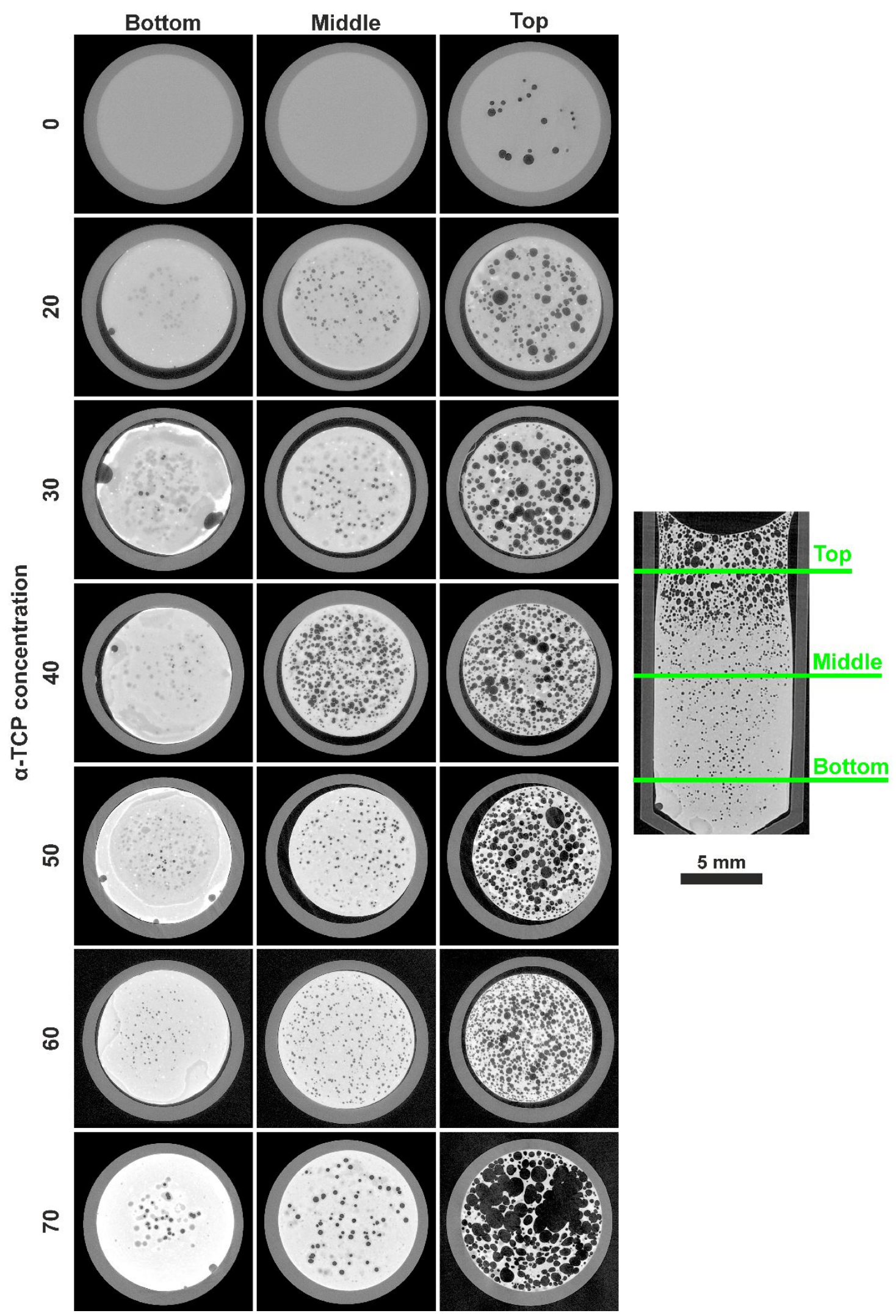

Figure 4. $\mu \mathrm{CT}$ analysis of the WPI/gelatin/CaP hydrogels - transverse sections extracted from the bottom, middle and top position of each sample. 


\subsection{Mineralization studies in SBF}


Figure 5. XRD patterns (A) and FTIR spectra (B) of the WPI/gelatin/CaP hydrogels after 14day incubation in SBF. XRD reflexes characteristic of hydroxyapatite are indicated by doted lines.

XRD and FTIR analyses showed further formation of CDHA phase in the composites upon incubation in SBF for 14 days. In the case of composite with the lowest initial content of $\alpha$-TCP (WPI/Gel/20TCP), the presence of reflexes characteristic of $\alpha$-TCP after incubation was not observed. XRD analysis of other materials revealed that intensities of reflexes characteristic of HA were significantly higher compared to those before soaking in SBF (Fig. 5A). Furthermore, they became more intense than reflexes arise from $\alpha$-TCP.

FTIR spectra of all composites after incubation in SBF exhibit bands characteristic of vibrations of $\mathrm{PO}_{4}{ }^{3-}$ groups in CDHA, namely double, sharp bands in the range of 563-603 $\mathrm{cm}^{-1}$, strong band at $1030 \mathrm{~cm}^{-1}$ with a shoulder at $1095 \mathrm{~cm}^{-1}$, as well as weak band at $865 \mathrm{~cm}^{-1}$ derives from $\mathrm{P}-\mathrm{O}(\mathrm{H})$ stretching vibrations of $\mathrm{HPO}_{4}{ }^{2-}$ (Fig. 5B). XRD pattern and FTIR spectrum of WPI/Gel hydrogel did not show any significant changes after incubation in SBF. 


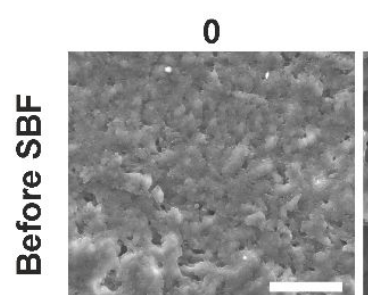

\section{$\alpha-$ TCP concentration}


40

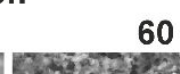

60
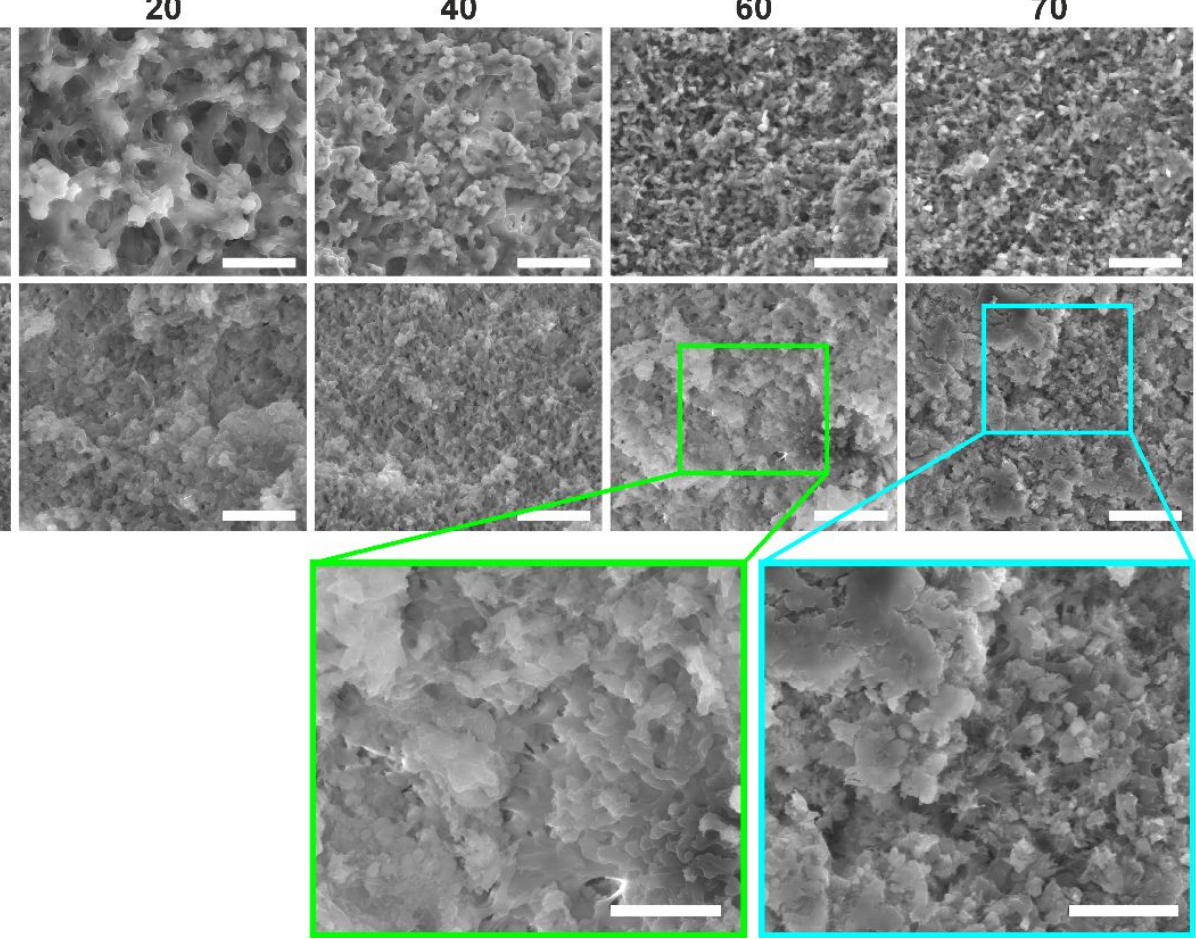

Figure 6. SEM images of the WPI/gelatin/CaP hydrogels before and after 14-day incubation in SBF at $5000 \times$ magnification (scale bar $10 \mu \mathrm{m}$ ) and at $10000 \times$ magnification (scale bar $5 \mu \mathrm{m}$ - colored frames).

SEM images of WPI/gelatin/CaP hydrogels before and after 14-day incubation in SBF are shown in Figure 6. After incubation, WPI/gelatin hydrogel showed significantly higher porosity and surface area than material before soaking in SBF, indicating degradation process of polymer matrix. Rouabhia et al. showed that WPI-based films underwent almost complete degradation within 60 days after subcutaneous implantation into Balb/c mice ${ }^{(24)}$. Because of different resorption time of individual components (WPI, gelatin, CaP phase), resulting composite hydrogels may show multistep degradation process in vivo. Furthermore, EDX analysis revealed that WPI/gelatin hydrogel was enriched in small amount of Ca after incubation (data not shown). In the case of WPI/gelatin/CaP composites, $\mathrm{CaP}$ spherical particles embedded in porous, polymer matrix were observed. Porosity of the composites decreased with increasing 
initial content of $\alpha$-TCP. Also incubation in SBF resulted in the reduction of material porosity. In the case of WPI/Gel/60TCP and WPI/Gel/70TCP composites, rod-shaped crystals, characteristic of HA derived from $\alpha$-TCP ${ }^{(25)}$, were visible after 14-day incubation in SBF.

A

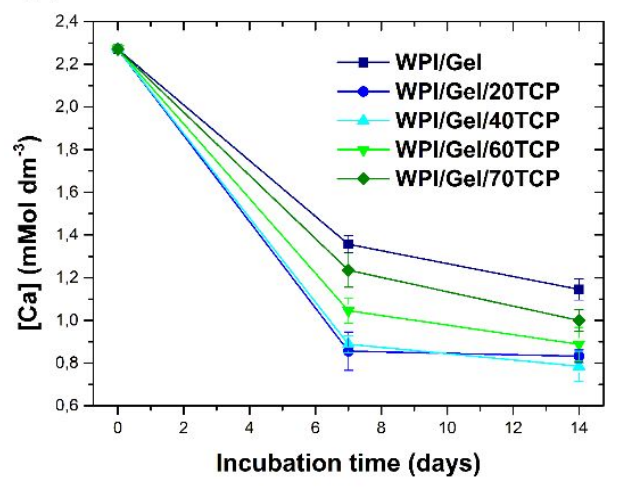

B

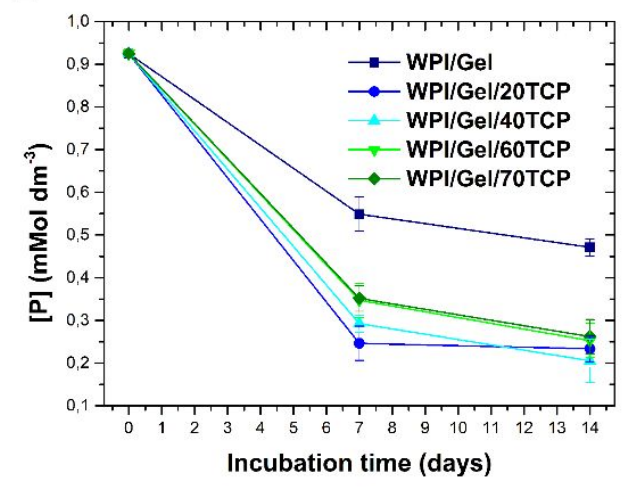

Figure 7. Changes of $\mathrm{Ca}(\mathrm{A})$ and $\mathrm{P}(\mathrm{B})$ concentrations in the SBF during 14-day incubation of WPI/gelatin/CaP hydrogels.

The changes in the concentrations of $\mathrm{Ca}$ and $\mathrm{P}$ in the SBF during 14-day incubation of WPI/gelatin/CaP hydrogels are shown in Figs. 7A-7B. For all hydrogels, $\mathrm{Ca}$ and $\mathrm{P}$ concentration decreased over incubation time, however the highest reduction was noticed within first 7 days. WPI/Gel material showed the lowest consumption of $\mathrm{Ca}$ and $\mathrm{P}$ from SBF, while in the case of composite hydrogels, the decrease, especially after 7 days, is inversely proportional to the initial content of $\alpha$-TCP in the materials. This is due to the fact that concentration of calcium and phosphate ions in SBF was affected both by $\alpha$-TCP dissolution and their consumption resulting from CDHA formation in materials.

\subsection{In vitro osteoblastic cell response}

Metabolic activity of the human osteoblast-like MG-63 cells cultured for 3 and 7 days in direct contact with hydrogels, corresponding to the number of cells, is shown in Figure 8. After 3-day culture, there was no significant difference between WPI/gelatin material and WPI/gelatin/CaP 
composite hydrogels, while after 7 days, the cells cultured on composite materials showed significantly higher metabolic activity. Furthermore, proliferation rate of osteoblastic-like cells cultured in direct contact with materials containing $\alpha$-TCP was higher compared to WPI/Gel hydrogel. Cell number on materials containing $\alpha$-TCP particles after both culture periods was on a similar level.

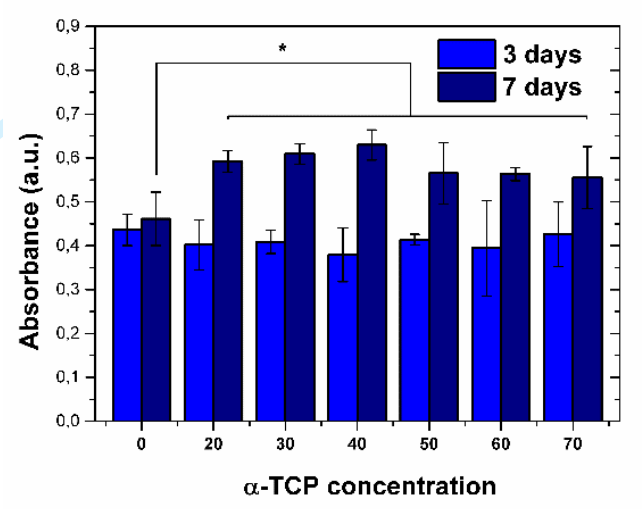

Figure 8. Metabolic activity (assessed by MTS assay) of the MG-63 cells cultured for 3 and 7 days in direct contact with WPI/gelatin/CaP hydrogels. Statistically significant differences (p $<0.05$ ) relative to the hydrogel unmodified with $\mathrm{CaP}$ are indicated by asterisk * (differences were detected only for 7-day culture). 


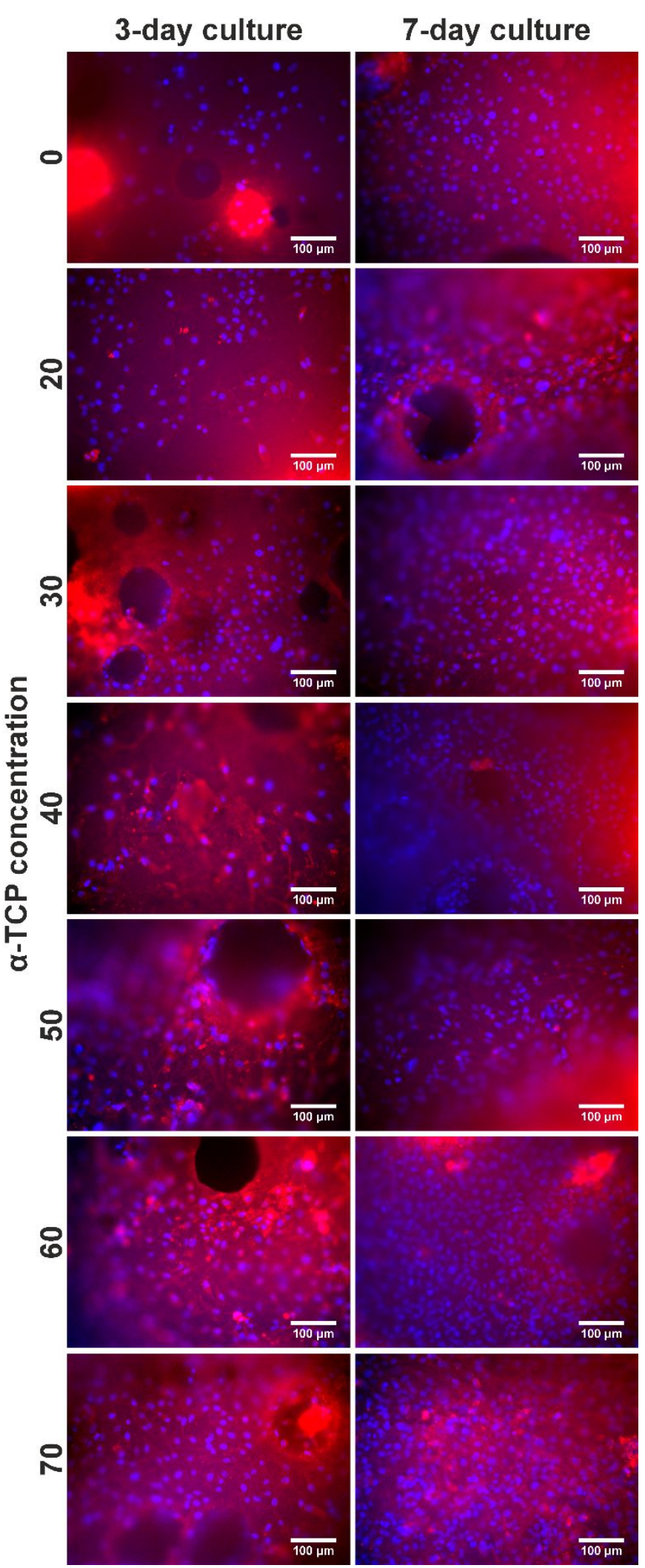

Figure 9. Confocal microscopy images of MG-63 cells cultured for 3 and 7 days in direct contact with hydrogels. Stained by Hoechst 33342 (nuclei, blue) and Texas Red C2 maleimid (cell cytoplasm, red). Scale bar $100 \mu \mathrm{m}$ (magnification 20×). 
Confocal microscopy images (Fig. 9) revealed that human osteoblast-like MG-63 cells were evenly distributed and attached to the surfaces of WPI/gelatin material and WPI/gelatin/CaP composite hydrogels just after 3-day culture. Cells exhibited well-spread and flattened morphology. Furthermore, many interconnections between cells were established through cellular extensions, allowing cell communication. After 7 days of culture, the number of cells was higher, especially on the surfaces of composite hydrogels, which is consistent with the results from metabolic activity measurement. MTS and microscopy results indicated that the WPI/gelatin/CaP composite hydrogels support the adhesion, spreading and proliferation of cells. Further studies are needed to explore cell behavior (e.g. differentiation process of boneforming cells) in direct contact with resulting hydrogels.

\section{Discussion}

$\alpha-\mathrm{TCP}$, in the form of fine powder, is widely used as the major component of various hydraulic calcium phosphate cements (CPCs). The setting reaction of CPCs is based on the hydrolysis of $\alpha$-TCP according to the following equation:

$3 \mathrm{Ca}_{3}\left(\mathrm{PO}_{4}\right)_{2}+\mathrm{H}_{2} \mathrm{O} \rightarrow \mathrm{Ca}_{9}\left(\mathrm{PO}_{4}\right)_{5}\left(\mathrm{HPO}_{4}\right) \mathrm{OH}$

$\alpha$-TCP in the presence of water or phosphate solutions dissolves and precipitates as CDHA, similar to bone hydroxyapatite ${ }^{(12)}$. However, there are not many studies concerning the use of $\alpha$-TCP as a component of composite hydrogels. In our recent work, it has been shown that $\alpha-$ TCP can be used to obtain self-gelling, injectable hydrogels based on polysaccharide gellan gum (GG). $\alpha$-TCP transformed to CDHA and also served as delivery vehicle for slow release of $\mathrm{Ca}^{2+}$ to enable GG internal crosslinking ${ }^{(14)}$. Recently, collagen/ $\alpha$-TCP composite hydrogels were produced using low temperature printing process ${ }^{(26)}$. However, for induction of $\alpha$-TCPCDHA transformation, incubation in phosphate buffer saline (PBS) at $37^{\circ} \mathrm{C}$ for $24 \mathrm{~h}$ was conducted. In turn, Goto et al. showed that hydrothermal treatment of PVA/ $\alpha$-TCP hydrogels at $120^{\circ} \mathrm{C}$ accelerates complete $\alpha$-TCP-CDHA transformation ${ }^{(25)}$. In contrast to our work, 
complete phase transformation in PVA-based composites may result from longer hydrothermal processing (6 h). Retarded $\alpha$-TCP-CDHA transformation in WPI/Gel/20TCP and WPI/Gel/30TCP composites may be related to a low amount of $\alpha$-TCP and thus reduced $\mathrm{Ca}^{2+}$ and $\mathrm{PO}_{4}{ }^{3-}$ concentrations resulting in low degree of supersaturation with respect to CDHA. This was additionally accompanied by high viscosity of hydrogel matrix which slows down the diffusion speed of both ions ${ }^{(27)}$.

Modification of hydrogel matrices with inorganic particles is a common strategy for improving mechanical properties of the materials. One of the most frequently used inorganic modifier is hydroxyapatite. Traditionally, HA/hydrogel composites have been fabricated by simple physical mixing of preformed HA particles with polymer solution. HA (nano)particles entrapped in the three-dimensional hydrogel network resulted in a significant improvement of compressive strength and modulus ${ }^{(28)-(30)}$. However, the approach proposed here, concerning incorporation of highly reactive $\alpha$-TCP particles followed by their in situ transformation to CDHA during hydrogel preparation process, may lead to more effective mechanical interlocking of inorganic phase in hydrogel network compared to preformed HA particles. In the case of $\alpha$-TCP-based cements, the hardening mechanism results from the entanglement of the precipitated CDHA crystals. Therefore, when $\alpha$-TCP-CDHA transformation occurs inside the hydrogel matrix, tightly connected organic-inorganic network would be formed ${ }^{(27)}$. This may result in higher mechanical strengths, stiffness, and hardness of resulting composite hydrogels.

Furthermore, the use of $\alpha$-TCP particles may have one more advantage over the modification with preformed HA particles. Calcium ions, released from $\alpha$-TCP to polymer solution, can interact with WPI and gelatin affecting mechanical properties of composite hydrogels. On the one hand, the presence of $\mathrm{Ca}^{2+}$ ions in the solution increases the rate of heat induced aggregation of WPI proteins, including $\beta$-lactoglobulin ${ }^{(31),(32)}$. On the other hand, it has been shown that the 
carboxyl ions of gelatin can bind $\mathrm{Ca}^{2+}$ ions which further interact with $\mathrm{PO}_{4}{ }^{3-}$ ions, providing nucleation sites for nanocrystals of HA ${ }^{(33)}$. Three effects that are responsible for calciuminduced protein aggregation have been proposed: intermolecular crosslinking of adjacent anionic groups by the formation of protein- $\mathrm{Ca}^{2+}$-protein bridges (i); hydrophobic interactions induced by ion induced conformation changes (ii); reduction of the negative charge of the proteins by binding of $\mathrm{Ca}^{2+}$ ions (iii) ${ }^{(31),(34)}$. $\mathrm{As}^{\mathrm{Ca}^{2+}}$ ions also bind specifically to whey proteins, similar mineralization mechanism of WPI would occur. Therefore, these two processes, namely calcium-induced protein aggregation, as well as the mineralization of gelatin and WPI, would improve mechanical properties of the composite hydrogels.

The issue of inhomogeneous distribution of inorganic fillers in hydrogel matrices is commonly known (35),(36). Inhomogeneous distribution of CaP phase in WPI/gelatin matrix may be attributed to aggregation of WPI induced by $\mathrm{Ca}^{2+}$ ions released from highly reactive $\alpha$-TCP. Previous studies have shown that $\mathrm{Ca}^{2+}$ ions induce the aggregation of WPI in solution even at ambient temperature ${ }^{(34)}$. Rapid dissolution of calcium ions would result in the formation of WPI aggregates around $\alpha$-TCP, hindering their uniform distribution in the WPI/gelatin solution. Ideally, the distribution of $\mathrm{CaP}$ phase would be homogeneous, however, a certain inhomogeneity does not preclude application as a biomaterial to support bone regeneration. Future work should focus on improving homogeneity. One of the strategies to improve the distribution of ceramic fillers in polymeric matrices is their functionalization or surface modification ${ }^{(37)}$. A second possible approach is to alter the zeta potential of the calcium phosphate particles by, for instance, changing the $\mathrm{pH}$ of solution ${ }^{(38)}$. These methods may lead to a reduction in the degree of agglomeration of the $\alpha$-TCP. Furthermore, materials with a gradient distribution of the $\mathrm{CaP}$ phase may be produced for e.g. bone-cartilage interface applications ${ }^{(39)}$. 
Our previous studies revealed that release of $\mathrm{Ca}$ and $\mathrm{P}$ ions from GG/ $\alpha$-TCP hydrogels, containing different concentration of $\alpha$-TCP (30-50 wt./vol.\%), was on similar level as was observed in present work ${ }^{(14)}$. However, $\alpha$-TCP in GG-based materials showed complete transformation to CDHA, which is much more stable phase. High reactivity in biologically related fluids of resulting composite hydrogels was ensured mainly by residual $\alpha$-TCP phase. $\alpha$-TCP produced by a wet chemical method has shown high reactivity and rapid transformation to CDHA ${ }^{(12)}$. This can lead to improvement of mechanical properties of hydrogels in the early stages after implantation to human body, in line with setting reaction of $\alpha$-TCP -based bone cements, and also provide bone-bonding ability.

The reduction of $\mathrm{Ca}$ concentration in SBF and also the presence of small amount of $\mathrm{Ca}$ in WPI/Gel hydrogel after incubation may confirm the calcium-binding capacity of gelatin and WPI. It was shown that whey proteins after heat-induced aggregation bind $\mathrm{Ca}^{2+}$ ions more easily (40). Although XRD, FTIR, and SEM/EDX analyses did not show mineralization of WPI/Gel upon incubation in SBF, calcium-binding capacity may additionally promote this process in composite hydrogels, where high degree of supersaturation can be induced by high solubility of residual $\alpha$-TCP phase.

To date, the response of bone-forming cells to whey proteins dissolved in cell culture medium was investigated. For instance, our recent research showed that the presence of WPI stimulates the expression of osteogenic differentiation markers (collagen 1 and alkaline phosphatase) by human adipose tissue-derived stem cells in a dose-dependent manner, as well as induces calcium deposition by human osteoblast-like Saos-2 cells even in growth culture medium without osteogenic supplementation ${ }^{(5)}$. Xu reported that the production of osteocalcin and insulin-like growth factor-I, as well as an expression of osteoprotegerin and receptor activator of nuclear factor-к B ligand (RANKL) by fetal rat osteoblasts increased upon treating them with whey proteins ${ }^{(41)}$. However, there are limited studies on cell behavior in direct contact 
with whey protein-based biomaterials. Gilbert and Rouabhia et al. prepared $\beta$-lactoglobulinand WPI-based films using casting method with addition of various plasticizers ${ }^{(42)}$. It is worth mentioning that heat treatment at $80{ }^{\circ} \mathrm{C}$ was used to denature the film-forming proteins. Resulting films have been shown to support attachment and growth of normal human keratinocytes and fibroblasts isolated from skin. Furthermore, subcutaneous implantation of the films into Balb/c mice revealed that materials were not toxic and immunogenic as well as did not provoke fibrous encapsulation ${ }^{(24)}$.

The incorporation of gelatin in other polymers is one of the strategies to improve their biological activity. For instance, Risser et al. showed that increasing concentration of gelatin in starchchitosan-gelatin composite foams have a positive effect on the growth and proliferation of MC3T3 mouse osteoblast cells ${ }^{(10)}$. In turn, the incorporation of gelatin in PVA electrospun nanofibers significantly improved the adhesion, spreading, and flattening of the 3T3 mouse fibroblasts ${ }^{(11)}$. This positive effect on cell behavior can be assigned to the presence of the arginine-glycine-aspartic acid (RGD) integrin-binding sequence of gelatin, including the A $\alpha$ chain and the heparin binding domain within the $B \beta$-chain which mediates cellmatrix(biomaterial) interactions.

Improved metabolic activity of MG-63 cells cultured for 7 days on WPI/gelatin/CaP composites might be ascribed to higher stiffness compared to WPI/gelatin hydrogel. Sen et al. showed that the osteogenic differentiation of human mesenchymal stem cells (hMSCs) can be altered by the addition of calcium phosphate ( $\beta$-TCP) in agarose and agarose-collagen hydrogels, as a result of increase in material stiffness ${ }^{(43)}$. On the other hand, $\mathrm{Ca}^{2+}$ and $\mathrm{PO}_{4}{ }^{3-}$ ions released from $\alpha-$ TCP as well as alkalization of culture medium have been shown to enhance osteoblastic function ${ }^{(44)}$. Furthermore, calcium-deficient hydroxyapatite (CDHA), present in composite hydrogels, shows easier biodegradation and higher cellular activities in comparison with stoichiometric hydroxyapatite ${ }^{(45)}$. 


\section{Conclusions and Outlook}

In the present work, novel multicomponent organic-inorganic hydrogel composites were prepared. Composites combine components commonly used in food industry, namely whey protein isolate and gelatin from bovine skin, as well as inorganic material commonly used as a major constituent of the hydraulic bone cements, namely $\alpha$-TCP in various concentrations ( 0 70 wt.\%). WPI was used for the first time as a component of composite hydrogels for tissue engineering applications. As a result of hydrolysis, $\alpha$-TCP underwent incomplete transformation to CDHA during preparation process of hydrogels. Microcomputer tomography showed inhomogeneous distribution of the $\mathrm{CaP}$ phase in the resulting composites. Nevertheless, hydrogels containing 30-70 wt. $\% \alpha$-TCP showed significantly improved mechanical properties. The values of Young's modulus and the stresses corresponding to compression of a sample by $50 \%$ increased almost linearly with increasing concentration of ceramic phase. Incomplete transformation of $\alpha$-TCP to CDHA during preparation process of composite hydrogels provides them high reactivity in simulated body fluid during 14-day incubation. Preliminary in vitro studies revealed that the WPI/gelatin/CaP composite hydrogels support proliferation, adhesion and spreading of human osteoblast-like MG-63 cells.

The WPI/gelatin/CaP composite hydrogels obtained in this work showed great potential for the use in bone tissue engineering applications. Taking into account fast gelation of gelatin at lower temperatures followed by heat-induced crosslinking of WPI, proposed material composition can potentially be processed using a low temperature 3D-printing technique to produce $3 \mathrm{D}$ scaffolds. However, further studies are needed to improve $\mathrm{CaP}$ phase distribution in WPI/gelatin hydrogel matrix.

\section{Acknowledgements}

MD, AZ, and AS acknowledge National Science Centre, Poland for financial support Grant No. 2017/27/B/ST8/01173. MD acknowledges financial support from the Foundation for Polish 
Science (FNP). MD and KCK acknowledge financial support from the Polish Ministry for Science and Higher Education Grant No. 11.11.160.365. TELD acknowledges the Research Foundation Flanders (FWO) for support in the framework of a postdoctoral fellowship. RK and LB acknowledge financial support from the Grant Agency of the Czech Republic („Center of Excellence“) Grant No. P108/12/G108.

\section{Conflict of Interest, Ethical Approval, Original Publication, and Author Contribution Statements}

The authors have no conflict of interest. No ethical approval was required for this study. No part of this work has been previously published or submitted for publication elsewhere. The authors made the following contributions to the paper:

Michal Dziadek and Timothy E.L. Douglas conceived, designed, planned and coordinated the study. Michal Dziadek fabricated the materials and wrote a large part of the manuscript. Michal Dziadek and Katarzyna Cholewa-Kowalska conducted incubation in SBF and subsequent FTIR (Figures 1B, 5B), as well as ICP-OES analysis (Figures 7A-7B) and mechanical tests (Figures 2A-2B), interpreted the data.

Svetlana Shkarina, Marcus Zuber, Venera Weinhardt, Tilo Baumbach, Maria A. Surmeneva, Roman A. Surmenev performed $\mu \mathrm{CT}$ measurements (Figures 3, 4).

Radmila Kudlackova and Lucie Bacakova performed cell biological characterization (Figures 8-9).

Magdalena Ziabka performed SEM analysis (Figure 6).

Piotr Jelen performed Raman analysis (Figure 1C).

Aneta Zima and Anna Slosarczyk developed a synthesis method, produced and provided $\alpha$-TCP powder. 
All authors contributed to writing parts of the paper and provided corrections as appropriate for preparation of the final version of the manuscript.

\section{References}

1. Jia X, Kiick KL. Hybrid multicomponent hydrogels for tissue engineering. Macromol Biosci [Internet]. NIH Public Access; 2009 [cited 2018 Sep 8];9:140-56. Available from: http:/www.ncbi.nlm.nih.gov/pubmed/19107720

2. de Castro RJS, Domingues MAF, Ohara A, Okuro PK, dos Santos JG, Brexó RP, Sato HH. Whey protein as a key component in food systems: Physicochemical properties, production technologies and applications. Food Struct [Internet]. 2017 [cited 2018 Sep 9];14:17-29. Available from:

https://linkinghub.elsevier.com/retrieve/pii/S2213329116300922

3. Ostojić S, Pavlović M, Živić M, Filipović Z, Gorjanović S, Hranisavljević S, Dojčinovič M. Processing of whey from dairy industry waste. Environ Chem Lett [Internet]. 2005 [cited 2018 Sep 9];3:29-32. Available from: http://link.springer.com/10.1007/s10311-005-0108-9

4. Gunasekaran S, Ko S, Xiao L. Use of whey proteins for encapsulation and controlled delivery applications. J Food Eng [Internet]. 2007 [cited 2018 Sep 9];83:31-40. Available from: http://linkinghub.elsevier.com/retrieve/pii/S0260877406006704

5. Douglas TEL, Vandrovcová M, Kročilová N, Keppler JK, Zárubová J, Skirtach AG, Bačáková L. Application of whey protein isolate in bone regeneration: Effects on growth and osteogenic differentiation of bone-forming cells. J Dairy Sci [Internet]. 2017 [cited 2018 Sep 8];101:28-36. Available from: https://linkinghub.elsevier.com/retrieve/pii/S0022030217309979

6. Pulat M, Akalin GO. Preparation and characterization of gelatin hydrogel support for 
immobilization of Candida Rugosa lipase. Artif Cells, Nanomedicine Biotechnol [Internet]. 2013 [cited 2018 Sep 9];41:145-51. Available from: http://www.tandfonline.com/doi/full/10.3109/10731199.2012.696070

7. Xing Q, Yates K, Vogt C, Qian Z, Frost MC, Zhao F. Increasing mechanical strength of gelatin hydrogels by divalent metal ion removal. Sci Rep [Internet]. Nature Publishing Group; 2014 [cited 2018 Sep 9];4:4706. Available from: http://www.nature.com/articles/srep04706

8. Maji K, Dasgupta S, Pramanik K, Bissoyi A. Preparation and Evaluation of GelatinChitosan-Nanobioglass 3D Porous Scaffold for Bone Tissue Engineering. Int J Biomater [Internet]. Hindawi Limited; 2016 [cited 2018 Sep 9];2016:9825659. Available from: http://www.ncbi.nlm.nih.gov/pubmed/26884764

9. Sarker B, Rompf J, Silva R, Lang N, Detsch R, Kaschta J, Fabry B, Boccaccini AR. Alginate-based hydrogels with improved adhesive properties for cell encapsulation. Int J Biol Macromol [Internet]. 2015 [cited 2018 Sep 9];78:72-8. Available from: http://dx.doi.org/10.1016/j.ijbiomac.2015.03.061

10. Risser GE, Banik BL, Brown JL, Catchmark JM. Structural properties of starchchitosan-gelatin foams and the impact of gelatin on MC3T3 mouse osteoblast cell viability. J Biol Eng [Internet]. BioMed Central; 2017 [cited 2018 Nov 1];11:43. Available from: https://jbioleng.biomedcentral.com/articles/10.1186/s13036-017-0086-

11. Huang CY, Hu KH, Wei ZH. Comparison of cell behavior on pva/pva-gelatin electrospun nanofibers with random and aligned configuration. Sci Rep [Internet]. Nature Publishing Group; 2016 [cited 2018 Nov 1];6:37960. Available from: http://www.nature.com/articles/srep37960 
12. Czechowska J, Zima A, Paszkiewicz Z, Lis J, Ślósarczyk A. Physicochemical properties and biomimetic behaviour of $\alpha$-TCP-chitosan based materials. Ceram Int [Internet]. Elsevier; 2014 [cited 2018 Sep 4];40:5523-32. Available from: https://www.sciencedirect.com/science/article/pii/S0272884213014144

13. Liu J, Zhao L, Ni L, Qiao C, Li D, Sun H, Zhang Z. The effect of synthetic $\alpha$ tricalcium phosphate on osteogenic differentiation of rat bone mesenchymal stem cells. Am J Transl Res [Internet]. e-Century Publishing Corporation; 2015 [cited 2018 Sep 9];7:1588-601. Available from: http://www.ncbi.nlm.nih.gov/pubmed/26550458

14. Douglas TEL, Schietse J, Zima A, Gorodzha S, Parakhonskiy B V., KhaleNkow D, Shkarin R, Ivanova A, Baumbach T, Weinhardt V, Stevens C V., Vanhoorne V, Vervaet C, Balcaen L, Vanhaecke F, Slośarczyk A, Surmeneva MA, Surmenev RA, Skirtach AG. Novel self-gelling injectable hydrogel/alpha-tricalcium phosphate composites for bone regeneration: Physiochemical and microcomputer tomographical characterization. J Biomed Mater Res - Part A [Internet]. Wiley-Blackwell; 2018 [cited 2018 Sep 4];106:822-8. Available from: http://doi.wiley.com/10.1002/jbm.a.36277

15. Paszkiewicz Z, Slosarczyk A. Method of manufacturing of reactive $\alpha$ tricalcium phosphate powder. 2013.

16. Kokubo T, Ito S, Huang ZT, Hayashi T, Sakka S, Kitsugi T, Yamamuro T. Ca, P-rich layer formed on high-strength bioactive glass-ceramic A-W. J Biomed Mater Res [Internet]. 1990 [cited 2018 Mar 26];24:331-43. Available from: http://www.ncbi.nlm.nih.gov/pubmed/2156869

17. Carrodeguas RG, De Aza S. $\alpha$-Tricalcium phosphate: Synthesis, properties and biomedical applications. Acta Biomater [Internet]. 2011 [cited 2018 Sep 20];7:353646. Available from: http://linkinghub.elsevier.com/retrieve/pii/S174270611100256X 
18. Kolmas J, Kaflak A, Zima A, Ślósarczyk A. Alpha-tricalcium phosphate synthesized by two different routes: Structural and spectroscopic characterization. Ceram Int [Internet]. 2015 [cited 2018 Sep 20];41:5727-33. Available from: http://linkinghub.elsevier.com/retrieve/pii/S0272884215000152

19. Ślósarczyk A, Paszkiewicz Z, Paluszkiewicz C. FTIR and XRD evaluation of carbonated hydroxyapatite powders synthesized by wet methods. J Mol Struct [Internet]. 2005 [cited 2018 Sep 20];744-747:657-61. Available from: http://linkinghub.elsevier.com/retrieve/pii/S0022286004009706

20. Vani R, Girija EK, Elayaraja K, Prakash Parthiban S, Kesavamoorthy R, Narayana Kalkura S. Hydrothermal synthesis of porous triphasic hydroxyapatite/( $\alpha$ and $\beta)$ tricalcium phosphate. J Mater Sci Mater Med [Internet]. 2009 [cited 2018 Sep 15];20:43-8. Available from: http://www.ncbi.nlm.nih.gov/pubmed/18560768

21. Siddharthan A, Seshadri SK, Sampath Kumar TS. Microwave accelerated synthesis of nanosized calcium deficient hydroxyapatite. J Mater Sci Mater Med [Internet]. 2004 [cited 2018 Sep 20];15:1279-84. Available from: http://link.springer.com/10.1007/s10856-004-5735-3

22. Koutsopoulos S. Synthesis and characterization of hydroxyapatite crystals: A review study on the analytical methods. J Biomed Mater Res [Internet]. 2002 [cited 2018 Sep 20];62:600-12. Available from: http://doi.wiley.com/10.1002/jbm.10280

23. Khan AF, Awais M, Khan AS, Tabassum S, Chaudhry AA, Rehman IU. Raman spectroscopy of natural bone and synthetic apatites. Appl Spectrosc Rev [Internet]. 2013 [cited 2018 Sep 20];48:329-55. Available from: http://www.tandfonline.com/doi/abs/10.1080/05704928.2012.721107

24. Rouabhia M, Gilbert V, Wang H, Subirade M. In vivo evaluation of whey protein- 
based biofilms as scaffolds for cutaneous cell cultures and biomedical applications. Biomed Mater [Internet]. 2007 [cited 2018 Nov 1];2:S38-44. Available from: http://www.ncbi.nlm.nih.gov/pubmed/18458418

25. Goto T, Kim IY, Kikuta K, Ohtsuki C. Hydrothermal synthesis of composites of wellcrystallized hydroxyapatite and poly(vinyl alcohol) hydrogel. Mater Sci Eng C [Internet]. 2012 [cited 2018 Nov 25];32:397-403. Available from: http://linkinghub.elsevier.com/retrieve/pii/S0928493111003298

26. Lee J, Kim G. Calcium-Deficient Hydroxyapatite/Collagen/Platelet-Rich Plasma Scaffold with Controlled Release Function for Hard Tissue Regeneration. ACS Biomater Sci Eng [Internet]. 2018 [cited 2018 Nov 24];4:278-89. Available from: http://pubs.acs.org/doi/10.1021/acsbiomaterials.7b00640

27. Christel T, Kuhlmann M, Vorndran E, Groll J, Gbureck U. Dual setting $\alpha$-tricalcium phosphate cements. J Mater Sci Mater Med [Internet]. 2013 [cited 2018 Oct 22];24:573-81. Available from: http://link.springer.com/10.1007/s10856-012-4828-7

28. Wu J, Liu J, Shi Y, Wan Y. Rheological, mechanical and degradable properties of injectable chitosan/silk fibroin/hydroxyapatite/glycerophosphate hydrogels. J Mech Behav Biomed Mater [Internet]. 2016 [cited 2018 Oct 21];64:161-72. Available from: https://linkinghub.elsevier.com/retrieve/pii/S1751616116302168

29. Li Z, Mi W, Wang H, Su Y, He C. Nano-hydroxyapatite/polyacrylamide composite hydrogels with high mechanical strengths and cell adhesion properties. Colloids Surfaces B Biointerfaces [Internet]. 2014 [cited 2018 Oct 21];123:959-64. Available from: https://linkinghub.elsevier.com/retrieve/pii/S0927776514006043

30. Gaharwar AK, Dammu SA, Canter JM, Wu CJ, Schmidt G. Highly extensible, tough, and elastomeric nanocomposite hydrogels from poly(ethylene glycol) and 
hydroxyapatite nanoparticles. Biomacromolecules [Internet]. 2011 [cited 2018 Oct 21];12:1641-50. Available from: http://pubs.acs.org/doi/abs/10.1021/bm200027z

31. Nicolai T, Britten M, Schmitt C. $\beta$-Lactoglobulin and WPI aggregates: Formation, structure and applications. Food Hydrocoll [Internet]. 2011 [cited 2018 Oct 21];25:1945-62. Available from: http://linkinghub.elsevier.com/retrieve/pii/S0268005X11000415

32. Phan-Xuan T, Durand D, Nicolai T, Donato L, Schmitt C, Bovetto L. Tuning the structure of protein particles and gels with calcium or sodium ions. Biomacromolecules [Internet]. 2013 [cited 2018 Oct 21];14:1980-9. Available from: http://pubs.acs.org/doi/10.1021/bm400347d

33. Chang MC, Ko CC, Douglas WH. Preparation of hydroxyapatite-gelatin nanocomposite. Biomaterials [Internet]. 2003 [cited 2018 Oct 22];24:2853-62. Available from: http://linkinghub.elsevier.com/retrieve/pii/S0142961203001157

34. Ju ZY, Kilara A. Aggregation Induced by Calcium Chloride and Subsequent Thermal Gelation of Whey Protein Isolate. J Dairy Sci [Internet]. 1998 [cited 2018 Oct 21];81:925-31. Available from: http://linkinghub.elsevier.com/retrieve/pii/S0022030298756528

35. Leeuwenburgh SCG, Jansen JA, Mikos AG. Functionalization of oligo(poly(ethylene glycol)fumarate) hydrogels with finely dispersed calcium phosphate nanocrystals for bone-substituting purposes. J Biomater Sci Polym Ed [Internet]. 2007 [cited 2018 Mar 27];18:1547-64. Available from: http://www.ncbi.nlm.nih.gov/pubmed/17988519

36. Leeuwenburgh SCG, Ana ID, Jansen JA. Sodium citrate as an effective dispersant for the synthesis of inorganic-organic composites with a nanodispersed mineral phase. Acta Biomater [Internet]. Elsevier; 2010 [cited 2018 Mar 27];6:836-44. Available 
from: https://www.sciencedirect.com/science/article/pii/S1742706109003973

37. Gao X, Guo G, Deng X, Fan R, Wang Y, Chen H, Fan M. Injectable thermosensitive hydrogel composite with surface-functionalized calcium phosphate as raw materials. Int J Nanomedicine [Internet]. 2014 [cited 2019 Jul 4];615. Available from: http://www.dovepress.com/injectable-thermosensitive-hydrogel-composite-withsurface-functionali-peer-reviewed-article-IJN

38. Chen CW, Oakes CS, Byrappa K, Riman RE, Brown K, TenHuisen KS, Janas VF. Synthesis, characterization, and dispersion properties of hydroxyapatite prepared by mechanochemical-hydrothermal methods. J Mater Chem [Internet]. 2004 [cited 2019 Jul 4];14:2425-32. Available from: http://xlink.rsc.org/?DOI=B315095J

39. Harley BA, Lynn AK, Wissner-Gross Z, Bonfield W, Yannas I V., Gibson LJ. Design of a multiphase osteochondral scaffold III: Fabrication of layered scaffolds with continuous interfaces. J Biomed Mater Res - Part A [Internet]. 2010 [cited 2019 Jul 4];92:1078-93. Available from: http://doi.wiley.com/10.1002/jbm.a.32387

40. Nguyen BT, Balakrishnan G, Jacquette B, Nicolai T, Chassenieux C, Schmitt C, Bovetto L. Inhibition and Promotion of Heat-Induced Gelation of Whey Proteins in the Presence of Calcium by Addition of Sodium Caseinate. Biomacromolecules [Internet]. 2016 [cited 2018 Oct 24];17:3800-7. Available from: http://pubs.acs.org/doi/10.1021/acs.biomac.6b01322

41. Xu R. Effect of whey protein on the proliferation and differentiation of osteoblasts. J Dairy Sci [Internet]. 2009 [cited 2019 Jan 4];92:3014-8. Available from: http://www.ncbi.nlm.nih.gov/pubmed/19528578

42. Gilbert V, Rouabhia M, Wang H, Arnould AL, Remondetto G, Subirade M. Characterization and evaluation of whey protein-based biofilms as substrates for in 
vitro cell cultures. Biomaterials [Internet]. Elsevier; 2005 [cited 2018 Nov 1];26:747180. Available from:

https://www.sciencedirect.com/science/article/pii/S0142961205004709

43. Sen KS, Duarte Campos DF, Köpf M, Blaeser A, Fischer H. The Effect of Addition of Calcium Phosphate Particles to Hydrogel-Based Composite Materials on Stiffness and Differentiation of Mesenchymal Stromal Cells toward Osteogenesis. Adv Healthc Mater [Internet]. 2018 [cited 2018 Nov 24];7:1800343. Available from: http://doi.wiley.com/10.1002/adhm.201800343

44. Ehara A, Ogata K, Imazato S, Ebisu S, Nakano T, Umakoshi Y. Effects of $\alpha$-TCP and TetCP on MC3T3-E1 proliferation, differentiation and mineralization. Biomaterials [Internet]. 2003 [cited 2018 Nov 24];24:831-6. Available from: http://linkinghub.elsevier.com/retrieve/pii/S0142961202004118

45. Guo H, Su J, Wei J, Kong H, Liu C. Biocompatibility and osteogenicity of degradable Ca-deficient hydroxyapatite scaffolds from calcium phosphate cement for bone tissue engineering. Acta Biomater [Internet]. 2009 [cited 2018 Nov 24];5:268-78. Available from: http://www.ncbi.nlm.nih.gov/pubmed/18722167 

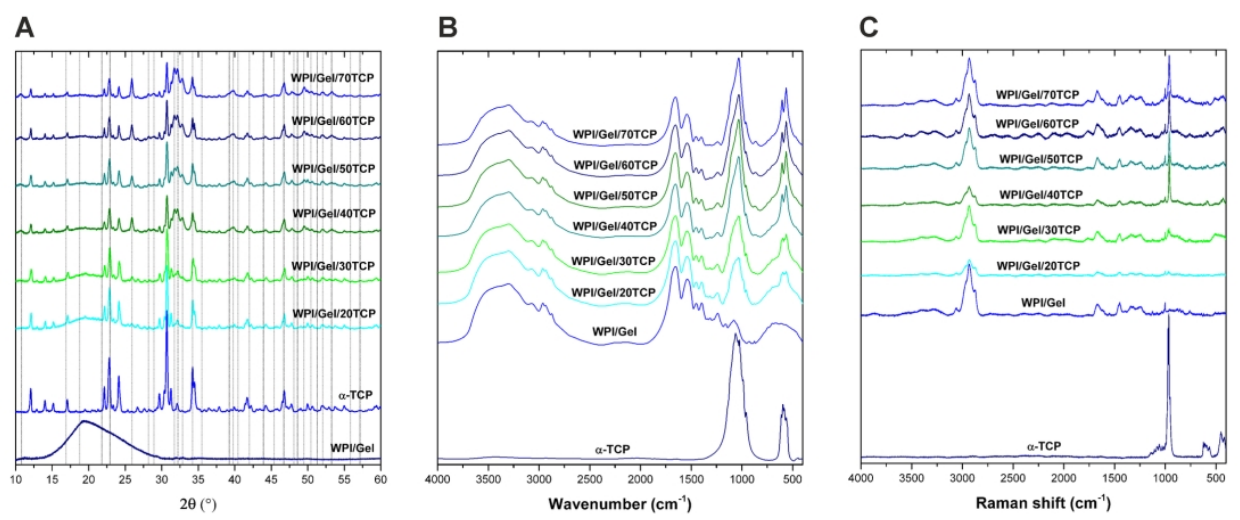

Figure 1. XRD patterns (A), FTIR (B) and Raman (C) spectra of the WPI/gelatin/CaP hydrogels. XRD reflexes characteristic of hydroxyapatite are indicated by doted lines.

\section{$194 \times 79 \mathrm{~mm}(300 \times 300 \mathrm{DPI})$}

John Wiley \& Sons, Inc. 
A

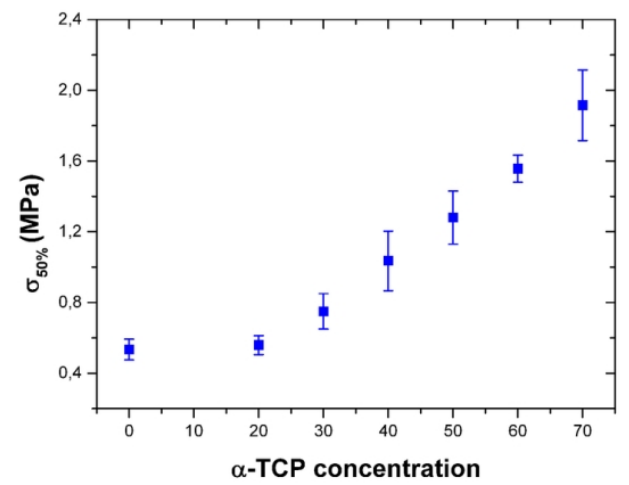

B

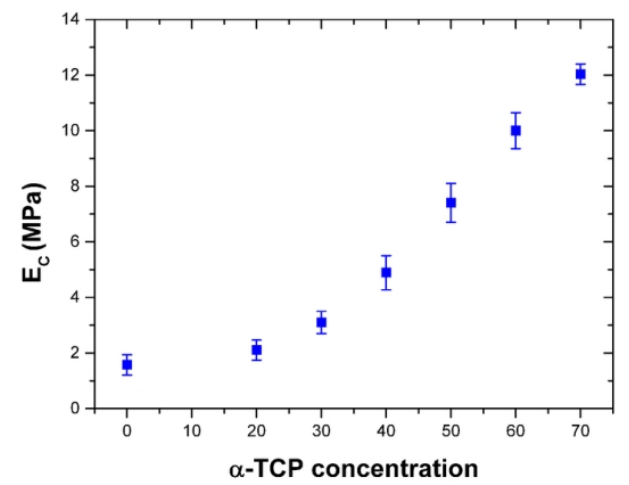

Figure 2. Compressive strength at $50 \%$ strain $\sigma 50 \%(A)$ and compressive modulus EC (B) of the WPI/gelatin/CaP hydrogel composites.

$130 \times 57 \mathrm{~mm}(300 \times 300 \mathrm{DPI})$ 

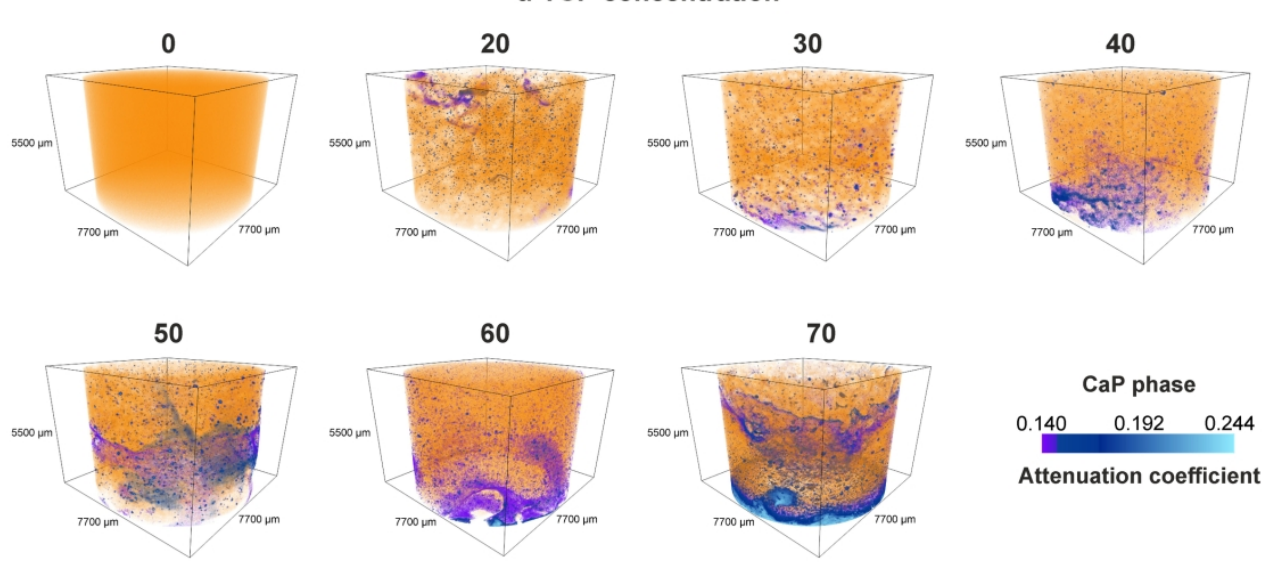

Figure 3. $\mu \mathrm{CT}$ analysis of the WPI/gelatin/CaP hydrogels - 3D rendering.

$205 \times 99 m m(300 \times 300$ DPI $)$

John Wiley \& Sons, Inc. 


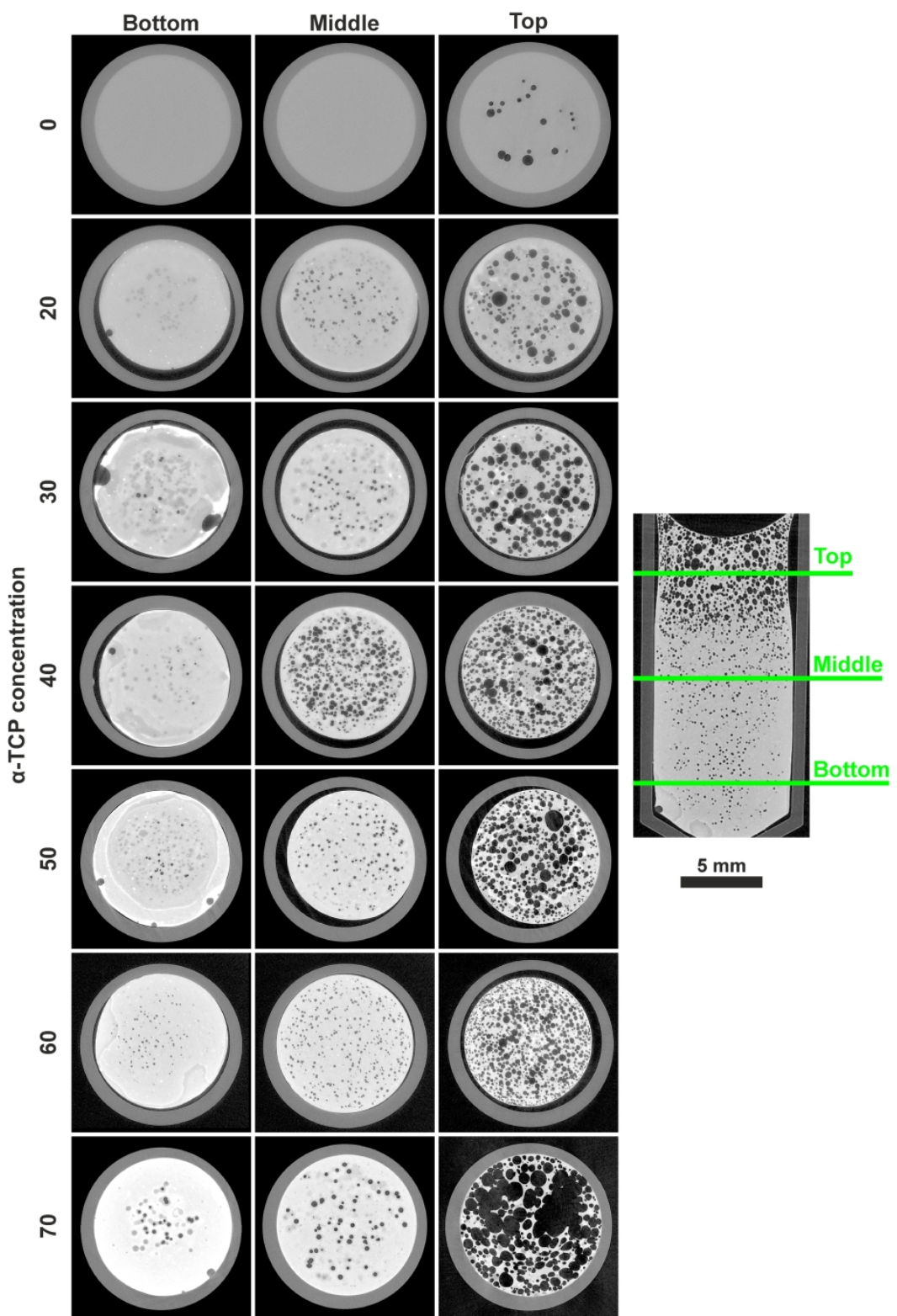

Figure 4. $\mu \mathrm{CT}$ analysis of the WPI/gelatin/CaP hydrogels - transverse sections extracted from the bottom, middle and top position of each sample.

$$
200 \times 292 \mathrm{~mm}(300 \times 300 \text { DPI })
$$



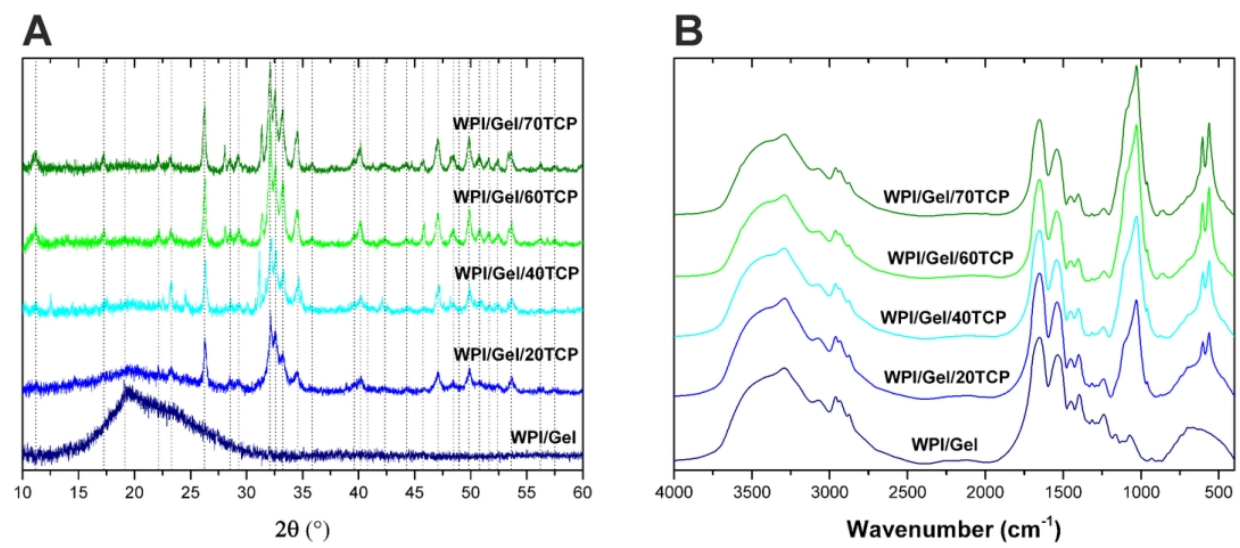

Figure 5. XRD patterns (A) and FTIR spectra (B) of the WPI/gelatin/CaP hydrogels after 14-day incubation in SBF. XRD reflexes characteristic of hydroxyapatite are indicated by doted lines.

$129 \times 55 \mathrm{~mm}(300 \times 300 \mathrm{DPI})$ 


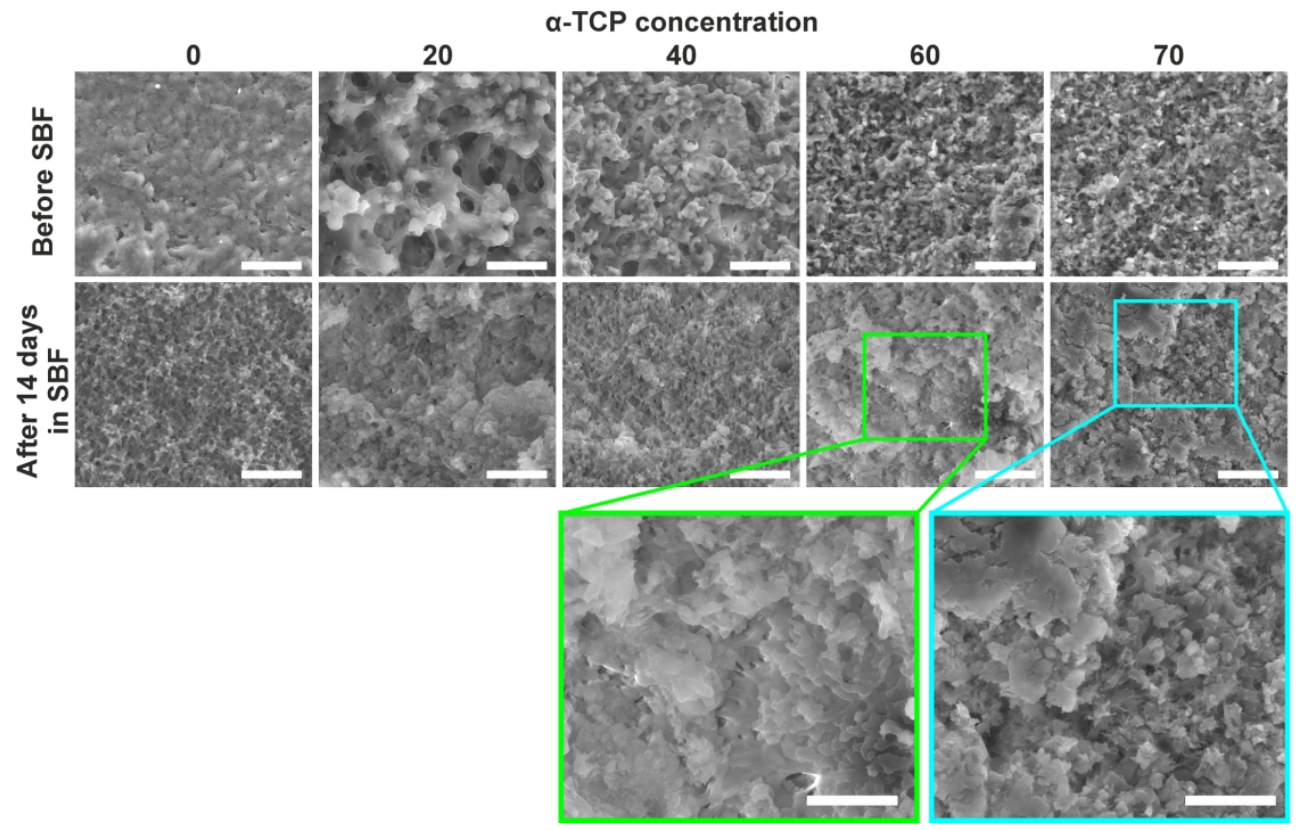

Figure 6. SEM images of the WPI/gelatin/CaP hydrogels before and after 14-day incubation in SBF at 5 000x magnification (scale bar $10 \mu \mathrm{m}$ ) and at $10000 \times$ magnification (scale bar $5 \mu \mathrm{m}$-colored frames).

$198 \times 127 \mathrm{~mm}(300 \times 300$ DPI $)$ 
A

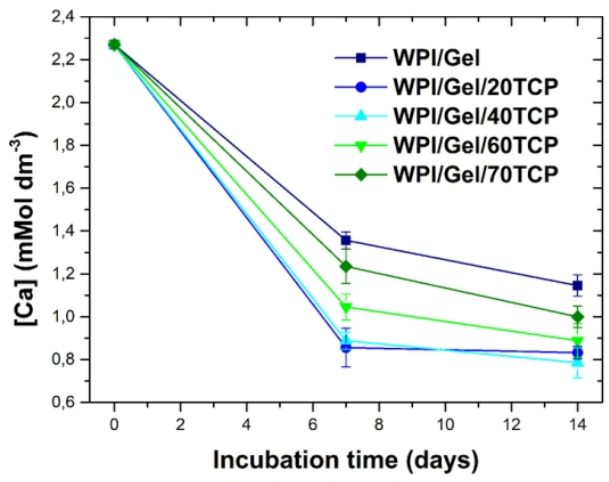

B

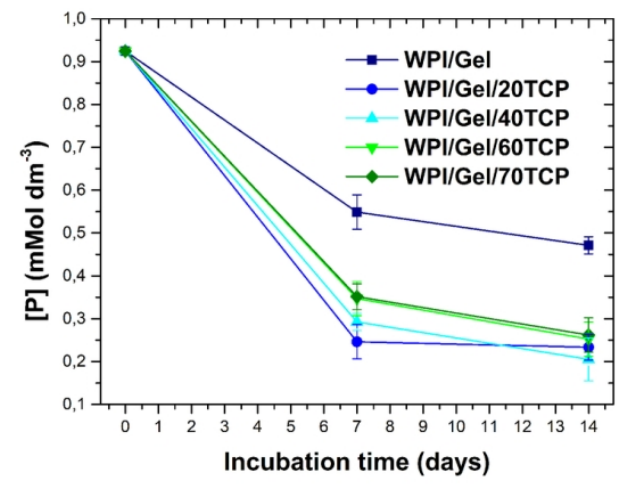

Figure 7. Changes of $\mathrm{Ca}(\mathrm{A})$ and $\mathrm{P}(\mathrm{B})$ concentrations in the SBF during 14-day incubation of WPI/gelatin/CaP hydrogels.

$131 \times 57 \mathrm{~mm}(300 \times 300$ DPI $)$ 


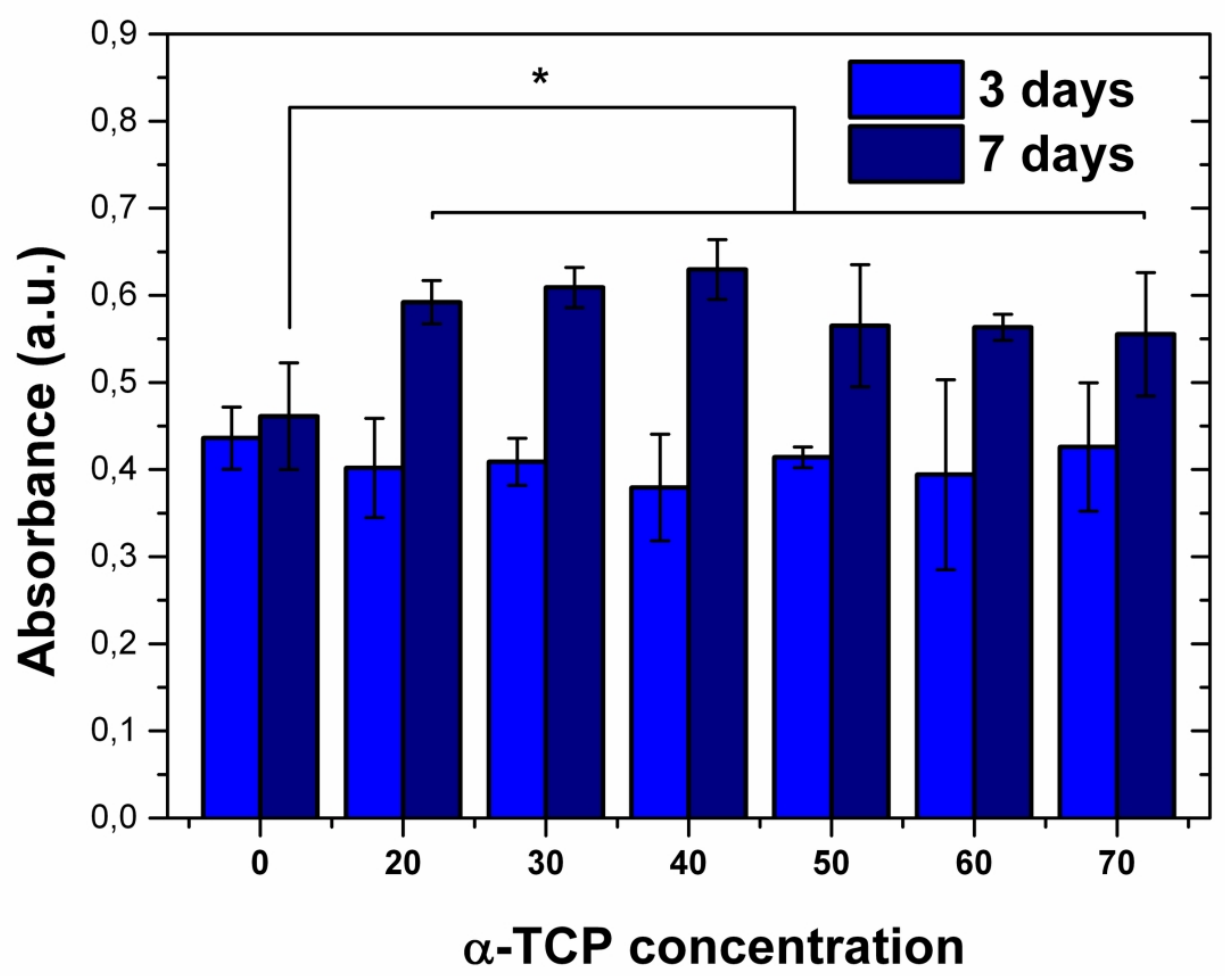

Figure 8. Metabolic activity (assessed by MTS assay) of the MG-63 cells cultured for 3 and 7 days in direct contact with WPI/gelatin/CaP hydrogels. Statistically significant differences $(p<0.05)$ relative to the hydrogel unmodified with CaP are indicated by asterisk * (differences were detected only for 7-day culture). $215 \times 177 \mathrm{~mm}(300 \times 300 \mathrm{DPI})$ 


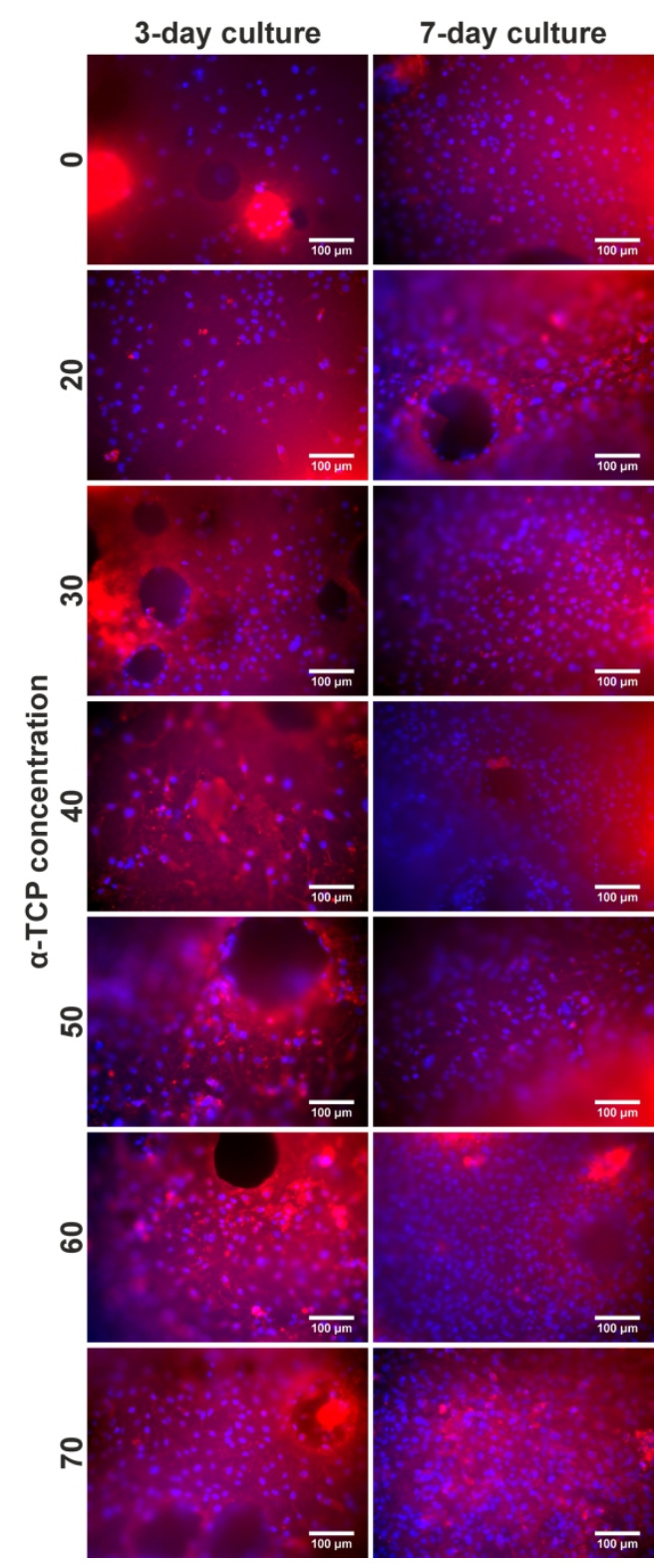

Figure 9. Confocal microscopy images of MG-63 cells cultured for 3 and 7 days in direct contact with hydrogels. Stained by Hoechst 33342 (nuclei, blue) and Texas Red C2 maleimid (cell cytoplasm, red). Scale bar $100 \mu \mathrm{m}$ (magnification 20x).

$122 \times 292 \mathrm{~mm}(300 \times 300 \mathrm{DPI})$ 